XIII.

\title{
Ueber den Ursprung und Verlauf der basalen Züge des unteren Lïngsbiindels.
}

Von

\author{
Niessl v. Mayendorf in Leipzig.
}

(Hierzu Tafeln I-IV.)

Unter den Faserzügen des Hemisphärenmarks ist der Fasciculus longitudinalis inferior in seinen leitenden Beziehungen zur Hirnrinde sowohl als zu den subkortikalen Ganglien am eifrigsten studiert worden. Ungeachtet mancher Meinungsverschiedenheiten im einzelnen, stimmen heute die Untersuchungsergebnisse darin überein, dass der Hauptstrom des unteren Längsbündels ein Projektionssystem sei, d. h. aus Kerngruppen des Sehhügels in die Rinde der Hinterhauptslappen ziehe. Nur die Wege der in den untersten Faseretagen gelagerten Bündel, so sehr sich die Aufmerksamkeit der Forscher gerade diesen auch zugewendet hatte, blieben im Dunkel oder erfuhren die strittigste Auslegung. Das hat wohl darin seinen Grund, dass die sichere Verfolgung dieser Züge nur nach Isolierung von der sie verhüllenden Umgebung möglich ist, welche reinliche Scheidung der Natur nur durch den glücklichen Zufall sekundärer Entartungen, als Folgen günstig situierter primärer Malazien gelingen kann. Andererseits ist es die geeignete Schrittrichtung, welche allein einen Ueberblick über längıre und wichtige Verlaufsstücke des basalen Lüngsbündelanteils zu geben vermag.

Da ich im Verfolge meiner Forschungen über die Zusammensetzung des menschlichen Hemisphärenmarks an ein Untersuctungsobjekt gelangte, welches zwar nur das typische Vorkommnis einer alten, die parieto-temporale Markwand zum grössten Teile auflösenden Malazie aufzuweisen hatte, jedoch durch, an diese sich anschliessende, weithin ausgebreitete Entartungserscheinungen in den umliegenden Markgebieten das von der primären Versehrung in seinem Gesamtlaufe verschonte Bündel, nackt, gleichsam herauspräpariert vor mir liegen sah, glückte es mir durch Anwendung einer ungewöhnlichen Schnittrichtung, indem ich schräg sagittal von aussen vorne nach hinten innen Ebenen legte, Archiv f. Psychiatrie. Bd. 61. Heft 2. 
durch eindentige Weigertbilder über Verhältnisse Licht zu verbreiten, über welche bisher nur subjektive Konstruktionen, zu welchen die vieldeutigen Frontalschnitte aus normalen Gehirnen dieser Gegend Aulass gaben, im Umlauf waren. Ehe ich mich zu dieser höchst einfachen, darum aber nicht minder schlagenden wesentlich illustrativen Beweisführung schildernd wende, sei dem Leser ein korzer Ueberblick über die historische Entwicklung der Anschauungen, wie sie sich nun mehr seit einem Jahrhundert über die in Rede stehende Faserung gebildet, fortgeerbt, modifiziert und bis in die jüngste Zeit mit manchen Wandlungen erhalten haben, geboten. Die Ungunst der Kriegsverhältnisse mit ihrer Schwierigkeit der Herbeischaffung literariscber. Behelfe mahne zur Nachsicht, wenn meine kritische Darstellung an mancher, vielleicht nicht unwichtiger Bearbeitung des Gegenstandes achtlos vorbeiging.

\section{I.}

Sobald man anfiug, an horizontalen Durchschnitten die Hirnfaserung zu betrachten, fiel dem naivsten Beobachter, wenn er die Schläfelappenbasis des auf dem Scheitel ruhenden Grosshirus angeschnitten hatte, eine temporale Umbeugung der basalsten Längsbündelfasern ins Auge. So erkennen wir diese unschwer wieder in dem Bündel $u_{1}$ einer primitiven, skizzenhaften Zeichnung, welche eine Abhandlung Reil's aus dem Anfang des vorigen Jahrhunderts bildtich zu beleuchten bestimmt war ${ }^{1}$ ). Dieses Bündel $u_{1}$ ist ein Faserkonvolut, „dass von der hinteren Extremität der Sehhügel kommt, und in Verbindung mit der Hirnschenkelorganisation das äussere Stratum des Seitenhorns gibt". Nach nach vorne ziehend, wendet es sich, unweit der Schläfelappenspitze, mit nach hinten offenem Winkel, wieder zurück.

Ebenso Friedricb Arnold2). In der Texterklärung zur Fig. 1, welche Abfaserungspräparate des Hirnmantels abbildet, signiert dieser Forscher den sehr deutlich herausgeschälten horizontalen Schenkel des unteren längsbündels mit $f$ und erläutert denselben also: „pes s. pars inferior anterior coronae radiatae". Die an einem Horizontalbild gut sichtbaren, vorne im Schläfelappen wieder nach der Mitte zu umbiegenden Bündel des Fasciculus longitudinalis fasst er als Fibrae coronae

1) Reil's und Antenrieth's Arch. f. Physiol. 1809. Bd. 9. Tab. 9. S. 193. Des Autors an peinliche Naturtreue gewobnte Gewissenhaftigkeit konnte an dem Fehlerhaften der Zeichnung im einzelnen nicht vorübergehen, obne es zu rügen, obgleich wir selbst an den rohen Konturen den richtigen Blick des Zeichners mit Genugtuung erkennen.

2) Fr. Arnoldi, Tabulae anatom. T'ab. 10. Fig. 1, S. 24. 
radiatae, welche den nach dem unteren und hinteren Lappen zustrebenden Faserzug zusammensetzen.

Meynerti), sich nur auf die willkürlich deutbaren Frgebnisse seiner Abfaserungsmethodik berufend, tadelt Arnold, weil er Reil's Irrtum wiederholend, das untere Längsbündel von einer Umbeugung des Stabkranzes ableite.

Burdach ${ }^{2}$ ), welcher in seinem vielgenannten Werke dem sich aus Assoziationsbündeln zusammensetzenden Mark den Namen Belegungsmasse gegeben hat, deren einzelne Glieder sich ihm als Verbindungen zwischen Grosshirnprovinzen darstellten und die Hauptmasse des Grosshirnmarks ausmachten, schliesst in die Bezeichnung "unteres Längsbündel" Fasciculus longitudinalis inferior nicht das gesamte Stratum sagittale externum von H. Sachs ein, sondern bloss dessen unterste Bündel, somit unsere basalen Züge des F.l.i., welche seiner Ansicht nach von der Spitze des Hinterlappens durch den Unterlappen bis zur Spitze des Vorderlappens in ununterbrochener Stetigkeit hinziehen. Er bilde die Grundlage der äusseren Wand des Unterhornes oder dessen äusseren Boden und stelle ein Geleis vor, in dem der Stabkranz verlaufe. Ein Teil derselben gehe unter dem Hackenbündel schräg (gemeint ist nach der Medianlinie $z u)$ nach vorne und imnen in die Spitze des Unterlappens (welchen wir jetzt als Schläfelappen bezeichnen); „der übrige Teil beugt sich nach vorue und innell, geht zum Stammlappen, unter dem Linsenkern hin"...

Burdach hat also den aufsteigenden Ast (unsere Pars descendens, wie wir ihn mit mehr Fug zu bezeichnen Grund haben), des F.l.i. gekannt, glaubte jedoch, während er die Faserung mit der Pinzette herausschälte, eine Fortsetzung desselben durch die äussere Kapsel hindurch in den Vorderlappen verfolgen zu können. Selbst wenn aber solch ein komplizierter Bündelverlauf existierte; -würde ihn Burdach mit der von ihm geübten Methode nicht haben finden können, denn ein Abreissen der Fasern an Umbeugungsstellen ist unvermeidlich. Was Burdach über seinem Hackenbündel bis in den Vorderlappen hinein sich begeben und die Spitze desselben erreicben sah, war in Wahrheit das Bogenbündel der Sylvischen Spalte. Die irrtümliche Zusammenfassung nahe bei einander liegender oder sich kreuzender Faserzüge zu einem einzigen ist einer der häufigsten Trugschlüsse, zu welchen der

1) Meynert, Neue Studien über die Assoziationsbündel des Hirnmantels. Sitzungsber. d. k. Akad. d. W. Mai 1892. Bd. 101. Abtlg. 3.

2) Burdach, Vom Leben und Bau des Gehirnes. Leipzig 1819. Bd. 2. S. $11 \mathrm{ff}$. 
durch Wegbruch der Rindenschale oder Wegschälen gewonnene Einblick in die Markformationen zu führen pflegt.

Dass das untere Längsbündel das Ammonshorn trage, ist ein weiterer Irrtum, welcher indes auf einer Anschauung fusst, die auch unter späteren, mit der Serienmethode arbeitenden Forschern sich recht verbreitet hat, und auf einer unrichtigen Zusammenfassung des gleichfalls aus langen Elementen gebildeten Markblattes des G. hippocampi mit dem F.l.i. beruht. Auf die wesentliche Verschiedenheit beider Systeme wird unten eingegangen werdea.

Luys') zeichnet auf den Tafeln XXX, XXXI, XXXII, XXXIII, XXXIV seiner Untersuchungen den Stabkranz des Hinterhauptlappens in schematisierten Horizontalschnitten ganz richig. Die Schärfe seiner Grenzen nach aussen, das krältige Kaliber seiner Markscheiden wird korrekt und sicher getroffen. Ebenso ist die Wendung medialwärts und der Eintritt des Stranges in die medialen Hinterhauptswindungen auf Fig. Taf XXX deutlich. Dasselbe Bild zeigt ferner, dass die Hinterhauptswindung, welche diese Einstrahlungen aufnimmt eine von innen tief einschneidende Furche der zweifellosen Fissura calcarina nach hinten zu abschliesst. Es ist somit der Eintritt der Gratiolet'schen Sehstrahlung in die Lippen der Fissura calcarina zutreffend veranschaulicht. Ein Horizontalschnitt durch die tiefsten-Hirnregionen (régions les plus inférieures) lässt die basalen Züge des F.l.i. mit seiner Umkehr im vorderen Schläfenlappen nach innen erscheinen. Fig. 2, Taf. XXIII versinnlicht den äusseren Kniehöcker (7) mit der aus ihm hervorgehenden Sehstrahlung, welche $\left(3,3^{\prime}\right)$ definiert wird als Fibres convergentes, recoorbées en crochet, des circonvolutions inférieures et internes. Nur Fig. 2 (Taf XXVII) gibt die Zeichnung eines von der Medianseite offenbar durch Bruch in sagittaler Richtung geöftneten Gehirns. Hier fällt der Blick auf ein langes Fasersystem zwischen Spitze des Schläfe- und Hinterhauptlappens ausgespannt. Ein anf dieses Gebilde hindeutender Buchstabe fehlt. Es besteht jedoch kein Zweifel, dass mit diesem der Fasciculus longitudinalis inferior Burdach's gemeint ist. Derselbe setzt sich nach der Zeichnung aus Faszikeln verschiedener Länge zusammen, wie ihn später Meynert, Dejerine und seine Schule darstellten. Solcher Auffassung ist er indes das längste aller Konduktorenbündel, welche sich peripherwärts ihm anlegen und die Furchen auskleiden. Würde er aber in Wahrheit zu diesen gehören, so müsste er in seiner Struktur, im Faserkaliber, in der Anordrung der Elemente, in der Epoche der Markreife mit ihnen übereinstimmen. Die mikro-

1) Luys, Recherches sur le Système Nerveux. Paris 1865. 
skopische Betrachtung eines gefärbten Schnittpräparates überzeugt jedoch von dem Gegenteil. Man müsste daher um die Realität des im Bilde postulierten Bündels zu retten, Assoziationsfasern postulieren, welche neben, bzw. nach aussen vom F.l.i. ihre Lage hätten.

Meynert's ${ }^{1}$ ) irrige Auffassung des unteren Längsbündels, unter welchem er die basalen Züge des Stratum sagittale externum verstand, erklärt sich aus der allzu rückhaltlosen Hingabe an seine durch Wegbruch der Hirnrinde und Abfaserung gewonnenen Präparate. Obgleich ihm die Bedeutung des fraglichen Bündels als eines Assoziationssystems, welches sich aus ungleich langen Fasern zusammensetzt, unverrückbar feststand, so schien er die Pars descendens aus dem äusseren Kniehöcker doch gekannt zu haben: „Mit den genannten Stabkranzbündeln nun . . kreuzt sich ein ansehnliches Konvolut feinerer, von der Spitze des Schläfelappens ausgehender Bündel. Von da verlaufen sie zuerst am Aussenrande des Traktus und von ihm aus wenden sie sich in längeren oder kürzeren Spiraltouren nach innen, um die innersten und kürzesten Faszikel in die Masse des äusseren Kniehöckers, die längeren, äusseren, zahlreicheren in die oberfächlichen Lagen der hinteren Sehhügelregion eintreten zu lassen." Da wir mit der feineren und zuverlässigeren Methode der fortlaufenden gefärbten Serienschnitte derartige Zuzüge zum äusseren Kniehöcker aus der Schläfelappenspitze nicht sichtbar zu machen vermögen und der hervorgehobene spiralenförmige Verlauf mit der doppelten Beugung des Bündels im Sehläfelappen und vor seinem Eintritt in den Kniehöcker auf eine gewisse Aehnlichkeit hinzuweisen scheint, so ist recht wahrscheinlich, dass mit dem geschilderten Bündel die absteigende Kniehöckerwurzel des F. 1. i. gemeint war. Hierfür spricht auch der Umstand, dass es sich nach Meynert's ${ }^{2}$ ) Darstellung un eine recht beträchtliche Fasermenge handelt, da nicht nur bei oberflächlicher Präparation ein ansehnliches Konvolut von Fasern hervortrat, sondern bei tieferem Eindringen abermals von der Schläfelappenspitze entspringende Faserungen sich zeigten . . , deren oberste sich gleichfalls, vom Aussenrande ber, in tiefere Lagen des äusseren Kniehöckers begeben.

Wenn man Dejerine's ${ }^{3}$ ) illustrative Beweise für die Existenz der langen Assoziationssysteme betrachtet, so sind es fast ausschliesslich Schemata normaler Abfaserungspräparate (siehe die Figuren 373, 376,

1) Meynert, Klinik der Erkrankungen des Vorderhirns. 1884. S. 39.

2) Meynert, Beiträge zur Kenntnis der zentralen Projektion der Sinnesoberflächen. IX. Ber. d. Sitz. d. Akad. d. Wissensch. 1869. II. Abt. Okt.-Heft.

3) Dejerine, Anatomie des Centres Nerveux. Paris 1895. T. 1. 
377, 381), welche wirkliche Verbindungen zwischen zwei Rindenstationen aufzeigen. Es sind graphisch vereinfachte Deutungen Burdach'scher und Meynert'scher Abbildungen. Dem unteren Längsbündel sind fünfzehn Seiten gewidmet. Er identifiziert mit Unrecht Burdach's Fasciculus longitudinalis inferior mit dem Stratum sagittale von Sachs. Seiner Meinung nach ist der grösste Teil der Fasern des F. 1. i. Assoziationsfasern, der basale Abschnitt des F. l.i. bestehe nur aus solchen. Sie entsprängen aus der Rinde des Hinterhauptspoles und aus derjenigen aller Okzipitalwindungen. "S. 771: Les fibres de couches inférieures se rendent dans la circonvolution de l'bippocampe." Dejerine rechnet also die langen Bündel im tiefen Mark der Hippokampuswindung, deren Bahn wir weiter unten bei der Schilderung der eigenen Präparate zur Sprache bringen, zu der Faserung des F.1.i., zu welcher er sicher nicht gehört. Ausserdem endige die basale Fasergruppe in der Spindelwindung, der dritten Schläfewindung, ein grosser Teil strahle in die zweite, und eine sehr grosse Anzahl (un plus grand nombre) in die Rinde der ersten aus und erreiche die Spitze des Schläfelappens. Fig. 386 auf S. 772 gewährt auf einem nach WeigertPal behandelten Horizontalschnitt durch den vordersten Schläfelappen einen Einblick in die örtlich nahen Beziehungen des F. 1. i. zu dem Mandelkern. Dejerine hält sogar den Mandelkern für die Endstation (!) des F. l. i. (Coupe horizontale du lobe temporale droit montrant la façon dont le faisceau longitudinal inférieur aborde le noyau amygdalien). In Wirklichkeit haben aber seine Fasern keine Verbindung mit diesem Kern, sondern steigen bart an seiner äusseren Kante aus dem Kuiehöcker herab. Da er sich in diesem Verlaufsstück mit der vorderen Kommissur, deren Zusammenhang mit dem Mandelkern wahrscheinlich ist, kreuzt und durchflicht, so kann allerdings bei Berücksichtigung von Schnittpräparaten nur einer Richtung der Anschein eines Konnexes zwischen F. l. i. und Nucl. amygdal. nicht geleugnet werdev.

Für Vialet' ${ }^{1}$, einem Schüler Dejerine's, welcher den basalen Zug des F.1.i. an Weigertpräparaten verschiedener Schnittrichtung studiert hat, besteht derselbe aus langen Assoziationsfasern, die sich besonders gut auf Horizontalschnitten der Beobachtung darbieten. Der F. l.i. gehe aus der Spitze des Hinterhauptslappens hervor und zerstreue sich wach vorne hin in verschiedenen Richtungen. Die Hauptmasse der Fasern endige im Schläfelappen, insbesondere in der ersten und zweiten Schläfewindung, und zwar dehne sich die Ausstrahlung

1) Vialet, Les Centres Cérébraux de la Vision. Paris 1893. 
Ursprung und Verlauf der basalen Züge des unteren Längsbündels. 279

bis zur Temporallappenspitze aus. Andere Fasern bögen. nach innen um und vermischten sich mit dem Stabkranz. Ein dritter Anteil beteilige sich an der Formation der äusseren Kapsel und ein vierter setze sich in Beziehung mit dem zweiten und dritten Segment des Linsenkernes.

H. Sachs ${ }^{1}$ ), welcher als einer der Ersten es unternahm, das menschliche Hemisphärenmark an nach Weigert-P al gefärbten Serienschnitten zu studieren, erklärt, ohne eine schlagende Beweisführung auch nur zu versuchen: „Die Fasern dieser Schicht (des Stratum sagittale externum) kommen aus der Rinde des Hinterhauptslappens, wie es scheint aus allen Teilen desselben, und gehen, mit Ausnahme eines kleinen Teils, zur Rinde des Scbläfelappens; sie bilden die - lange - Assoziationsbahn dieser beiden Rindenabschnitte". I)ass Sachs damil den basalen Zug des F.l.i. im Auge bat, geht aus dem nächsten Satz hervor: „Um zu ihrem Ziele, zunächst in das Marklager des Schläfelappens zu gelangen, miissen sie sich schliesslich insgesamt an der unteren Fläche des Ventrikels sammeln“.... S. 14: „Nachdem das Stratum sagittale externum in den Schläfelappen gelangt ist, wird es sehr schnell wieder dünner, indem es nach allen Seiten in die Rinde Fasern abgibt. Ein grösserer Teil der Fasern aus dem äusseren Anteil und dem Fuss der Schicht lässt sich beim Zerfasern (!) in die erste Schläfewindung verfolgen, ein kleinerer gelangt in die zweite Schläfewindung, der Rest läuft immer unbedeutender werdend, gegen die Spitze des Schläfelappens hin und verschmilat untrennbar mit den übrigen, bier nach vorne strebenden Fasern des Schläfelappens. Die am weitesten nach vorn gelangenden Fasern der Schicht finden ihr Ende in der Spitze dieses Lappens."

Sachs ist, wie die meisten Erforscher des Verlaufs des F.l.i., ein Opfer seiner Methode geworden, die ihm nur unklare mehrdeutige Bilder lieferte. So ist es geradezu unmöglich, Ursprung, Verlauf und Ende des basalen unteren Längsbündels auf Frontalschnitten normaler Weigertpräparate auch nur annähernd zu bestimmen, geschweige denn, dass sich mit der Abfaserung das Ende desselben in den Sehläfewindungen auch nur anä̈hernd feststellen liesse. Sachs stebt bei der Deutung der ihm vorliegenden anatomischen Bilder ganz im Banne seiner Vorgänger.

Einen Wendepunkt in der Geschichte der Anschauungen üher das untere Längsbündel bedeutet Flechsig's²) kurze, aber wichtige Mit-

1) H. Sachs, Das Hemispbärenmark des menschlichen Grosshirns. Leipzig 1892.

2) Flechsig, Weitere Mitteilungen über den Stabkranz des menschlichen Grosshirns. Neurol. Zentralbl. 1896. 
teilung, dass der Fasciculus longitudinalis inferior nichts weiter als ein Teil der Sebstrahlung Gratiolet's sei. Die fraglichen Bündel endigten, wie er nachweisen konnte, allerdings nach hinten im Hinterhauptslappen, speziell in der Sehsphäre, nach vorne hin verbänden sie sich aber nicht mit der Rinde, sondern mit dem Thalamus opticus: "Sie machen hierbei einen beträchtlichen Umweg, indem sie im Schläfelappen nach vorne laufen bis zur Gegend unmittelbar nach aussen vom Mandelkern und hier nach oben umbiegen mit zum Teil spitzwinkliger Knickung, so dass sie das Unterhorn von vorne her umgreifen". Im 37. Band des Archivs für Psychiatrie habe ich Flechsig's Standpunkt hinsichtlich seiner Auffassung des F.l.i. als eines Projektionssystems und seiner Umbeugung im vorderen Schläfelappen bestätigen könneu ${ }^{1}$ ). Auch die Fig. 1 meiner dort publizierten Arbeit beweist schlagend die "spitzwinklige" Umkehr mancher Bündel. Anders verhält es sich freilich mit den von Flechsig angegebenen Endigungsgebieten des F. 1. i. im Sehbügel. "Im Tbalamus", meinte damals Flechsig, "treten sie (die Faserzüge des F.l. i.) teils mit den basalen Absebnitten des Lateralkernes bzw. dem schalenförmigen Körper in Verbindung", zum Teil stiegen sie an der hinteren Fläche des Pulvinar im Stratum zonale in die Höhe und gelangten in den Hauptkern. „Sie durchflechten bierbei“, heisst es weiter, „ein starkes Faserbündel, welches von der oberen Fläche des äusseren Kniehöckers aus durch das Pulvinar zum Stratum zonale zieht, und hängen die Fasern beider Bündel wohl zusammen."

Dagegen erfahren wir aus der unten gegebenen Schilderung unserer Präparate, dass der Fasciculus longitudinalis inferior Burdacb's, welcher nur mit den basalen Zügen der primären Sehstrahlung Flechsig's identisch ist, aus einer sehr beschränkten Zone des Zwischenhirns, und zwar nur aus dem schmalen lateralen Abschnitt des äusseren Kniehöckers, aus dessen Spornteil entspringt, mit dem hochgradig atrophisch eingezogenen Pulvinar aber nicht in leitendem Zusammenhang stehen kann.

In der, im gleichen Jahre erschienenen, jedoch bereits 1894 gehaltenen Rektoratsrede ${ }^{2}$ ) bezeichnet Flechsig den Sehhügelursprung des F.l. i. geradezu als "Strahlung des äusseren Kniehöckers", welcher von der hinteren, äusseren, oberen Fläche dieses Ganglions ausgehend, einen Fächer bilde, sich bis zum oberen Sehhügelrand erstreckte und zum Teil unter steilen Umbiegungen in die Sehstrahlung übergehe.

1) Niessl v. Mayendorf, Vom Fasciculus longitudinalis inferior. Arch. f. Psych. Bd. 37. S. 13.

2) Flechsig, Gehirn und Seele. Leipzig 1896. S. 72. 
Flechsig macht in der zue!st zitierten Notiz darauf aufmerksam, dass der F.l.i. auf seinem Weg vom Sehhügel zur Aussenseite des Unterhornes von Stabkranzbündeln des Thalamus begleitet werde, welche zur Riechsphäre und zum Ammonshorn zögen und aussen vom Mandelkern nach vorn umbögen. Hierdurch entstünde der Anschein, als ob Fasern des Fasciculus longitudinalis inferior zur Hackenwindung usw. zögen. Flechsig's Hinweis ist sehr wesentlich, leider aber von späteren Autoren viel zu wenig beachtet worden. Ganz besonders unterlagen der Täuschung solche, wrlche das Gehirn nur an Frontalschnitten untersuchten. Die fraglichen Bündel geben mit dem F.l.i. nämlich ihrem Faserkaliber, ihrer Gruppierung, sowie ihrer engen Nachbarschaft den Anschein einer anatomischen Einheit. Dass dieses Bündel der Hippokampuswindung mit dem F. l. i. nicht das Geringste zu tun hat, beweist schon der Umstand, dass es zu dem Ersteren beim Erscheinen erwähnter Windung medialwärts erst hinzutritt. Es degeneriert daher auch nicht, wenn eine Zerstörung in den Hinterhauptslappen auf den inneren Schläfelappen nicht übergreift.

Dagegen erklärt v. Monakow ${ }^{1}$ ): "Das Stratum sagittale ext. enthält neben durchziehenden Projektions- und Balkenfaseru bauptsächlich lange Assoziationsfasern, unter welchen die Verbindung zwischen Okzipitalwindungen und den oberen Temporalwindungen die wichtigste ist (ventraler Abschnitt des F. I. i.)." Es geht jedoch aus der Verfolgung der sekundären Degenerationen bei der Analyse seiner, sowie der von ihm zitierten Beobachtungen nirgends der Nachweis hervor, dass der ventrale Abschnitt des F. 1. i. im Hinterhauptslappen entspringt und im Schläfelappen endigt oder umgekehrt. Im Gegenteil findet sich im Fall 2 (Märki), welcher eingehend anatomisch untersucht wurde, ein mit dem unten mitzuteilenden Ergebnis unserer eigenen Untersuchung ganz analoges Verhalten. Der alte Erweichungsherd liegt im unteren linken Scheitellappen. Entartet ist, wie Textfig. 2, S. 47 dartut, der gesamte dorsale F.l.i., der ventrale bingegen ist vollkommen normal. "Dieser intakt gebliebene Faserzug wandte sich direkt in das sogenannte Mark des C.g. e., dessen Hauptbestandteil er bildete, um von hier aus teils in die hintere Hälfte des C. g. e. einzutreten, teils in andere Teile des Sehhügels überzugehen" ... „Die dem erwähnten Markabschnitt zugehörige Partie des C. g. e. (die okzipital-laterale Hälfte) ist verschont geblieben. Dabei fallen sowohl auf den schematischen Abbildungen als in der Beschreibung beide Strata, das interue und externe zn-

1) v. Monakow, Zur Anatomie und Pathologie des unteren Scheitelläppchens. Aroh. f. Psych. 1899. Bd. 31. 
sammen (v. Monakow spricht von den Sehstrahlungen). An anderer Stelle S. 54 identifiziert er nur das Stratum sagittale internum mit den Sehstrahlungen, es hat daher den Anschein, als ob er die Kniehöckerstrahlungen sich ausschliesslich aus diesem zusammensetzen liess, was wie, wir unten sehen werden, unser Fall vollkommen ausschliesst. Ebenso zuverlässig können im unteren Längsbündel Projektionsfaserzuzüge aus den basalen Temporalwindungen und dem G. hippocampi nach unseren Präparaten negiert werden. In einem von v. Monakow früher mitgeteilten Falle (Kuhn, Arch. f. Psych., Bd. 23) war die Lage des primären Herdes dieselbe und die sekundären Degenerationen in den Strata sagittalia wieder die gleichen, so dass der Autor die ihm aufstossende Gesetzmässigkeit dahin ausspricht: die hintere und laterale Partie des äusseren Kniehöckers entsendet ihre Hinterhauptsstrahlung nach den medialen Hinterhauptswindungen.

v. Monakow, welcher hier noch mit älteren Methoden (hauptsächlich Karminfärbung und nur Frontalschnitten) gearbeitet, identifiziert den F.l.i. mit dem Stratum externum, ror allem dieses auch mit dem Stratum internum, da ihm seine Präparate über die anatomische Verschiedenheit und scharfe Abgrenzbarkeit beider Schichten keine Klarheit geben kounten.

Römer ${ }^{1}$ ) findet bei seinen myelogenetischen Studien den F. I. i. an dem jüngsten (1 Monat alten) Kindergehirn markhaltig, in einem Entwicklungsstadium, in welchem "weder innerhalb des Temporalhirns, noch innerhalb des Okzipital- und Frontalhirus sich gefärbte Fasern fanden, die als Assoziationsfasern anzusehen waren". Er vermag die getrennten drei Schichten von H. Sachs um das Hinterhorn nicht zu bestätigen, vor allem hält er die funktionelle Verschiedenheit derselben für nicht bewiesen. Er stellt sich daher auf die Seite Flechsig's und erblickt in dem unteren Längsbündel einen Projektionsfaserzug. Auch will Römer an einem Sagittalschnitt durch ein vier Monate altes Kind "den Uebergang von Fasern aus der inneren Kapsel heraus" in die intensiv gefärbte (fälschlich als Fasciculus longitudinalis inferior aufgefasste) Schicht der sogenannten Radiatio occipitothalamica auf das Bestimmteste erkennen. Ueber Ursprung, Endigung und Beschaffenheit der basalen horizontalen Bündel des F. l. i. spricht sich Verf. nicht aus.

Schellenberg's unter der Führung v. Monakow's verfasste, schätzenswerte Arbeit ${ }^{2}$ ) beschäftigt sich mit der Darlegung der Mark-

1) Römer, Beiträge zur Auffassung des Faserverlaufs im Gehirn. Marburg 1900. Inaug.-Diss.

2) Schellenberg, Untersuchungen über das Grosshirnmark der Ungulaten. Diss. Zürich 1900. 
fasersysteme des Hemisphärenmarks der Ziege, des Schafs, des Rindes, des Pferdes, des Schweines, indem er dieses Material durch Heranziehung von „Gehirnen dreier neugeborenen Ziegen, die an der Hirnoberfläche operiert wurden, und eines mit Enukleation des Augapfels bereicherte. Den langen Assoziationsbündeln werden 5 Seiten gewidmet. Der Faseiculus longitudinalis inferior ist bei diesen Tierspezies sehr kräftig entwickelt und übertrifft an Fasermasse weit das Stratum sagittale internum, welches sich von ersterem scharf abhebt. Es besteht also hier das umgekehrte Verhältnis wie im Mensehenhirn. Während wir ferner von den meisten Beschreibern des F.l.i. im Menschenhirn eine Verkleinerung des Faserareals nach vorue zu vermerkt finden, wächst dieses Bündel nach Schellenberg's Angabe bei den Ungulaten von hinten nach vorne. Sowohl die Ersteren als der Letztere ziehen den Schluss, dass eine Aenderung der Fasermenge an der Aeuderung des Gesamtfaserquerschnittes, welcher den Beobachtungen zu Grunde gelegt wurde, die Schuld tragen müsse, und so führen die Einen die Verkleinerung derselben auf Faserabgabe, der Audere auf Faserzuwachs zurück. Beide folgern hieraus weiter leitęnde Beziehungen des Bündels zu der Rinde der umgebenden Windungen. Da man über das eine Ende des F.1. ị. im Hinterhauptslappen gewiss zu sein schien, wollte man in diesen $\mathrm{Ab}$ - und Zıgängen an Fasern einen Beweis für das Vorhandensein von Assoziationsfasern in demselben erblicken.

Bei diesem Anlass kann icb es mir nicht versagen, gegen eine solche Argumentation Verwahrung einzulegen. Es geht nicht an, aus der scheinbaren Vergrösserung oder Verkleinerung des Gesamtquerschnitts auf einen Zuwachs oder Abgang von Fasern ohne weiteres zu schliessen, denn sobald eine Faser schräge getroffen wird, nimmt sie im Vertikotransversalschnitt weit mehr Raum ein und die Grenzen der ganzen Faserschicht rücken auseinander. Hier müsste denn doch der Nachweis eines analogen Verhältnisses auf Ebenen verschiedener Schnittrichtung ebenso wie die annähernd numerische Feststellung bestätigend hinzutreten.

Dass, wenigstens ein Teil des ventralen F.l.i., welcher wie beim Menschen in der Richtung gegen den Lobus pyriformis und das temporale Operkulum verfolgt werden könne, in die innere Kapsel hinaufsteige, um sich im Sehhügel aufzulösen und dass man nur wenig mehr von diesem Bündel über die letzten Ausläufer des äusseren Knieböckers hinaus entdecken könne, wird von Schellenberg zugegeben. Auf Grund v. Monakow's und eigener Experimente dünkt es ihm jedoch als sehr wahrscheinlich, dass ein nicht unbeträchtlicher Bruchteil der sagittal verlaufenden Fasern des F. J.i. eine Verbindung zwischen dem 
Okzipitallappen, dem Lobus pyriformis und den Operkularwindungen herstelle. $\mathrm{Za}$ solcher Anschauung konnte aber Schellenberg nur gelangen, wenn er die im Lobus pyriformis ziehende Fasergruppe, welche mit derjenigen des G. hippocampi des menschlichen Gehirns korrespondiert, als einen einzigen Faserzug, als den F.l.i. ansprach, ein immer und immer wiederkebrender Irrtum, welcher die Fabel von dem im F.l.i. verlaufenden Assoziationssystem nicht verstummen liess. Es ist ganz richtig, dass der Fasciculus G. hippocampi in genannter Windung, also im Schläfelappen sein Ende findet, aber er hat, wie unten zur Sprache kommen wird, mit dem Hinterhauptslappen nichts zu tun.

Edinger ${ }^{1}$ ) verfolgt in seiner Arbeit sekundäre Degenerationen mit der Marchimethode an Frontalschnitten durch ein Gehirn, von welchen, wie Fig. 1 zeigt, fast alle drei Schlafewindungen bis zu ibrem Uebergang in die Scheitelwindungen chirurgisch entfernt worden waren. Operiert wurde am 27. September und am 26. Dezember starb Patient. Das Gehirn lag Wochen hindurch in Kali bichromicum und Ueberosmiumsäure.

Edinger bemerkt S. 316 ganz zutreffend, dass sein Fall nicht geeignet sei, eine Entscheidung in der Frage herbeizuführen, ob der Tractus occipito temporalis ein Projektionssystem oder ein Assoziationssystem sei, weil die Abtrennungsstelle des Schläfelappens etwa in der Gegend liege, wo die Fasern in den Thalamus einstrahlen müssten, und doch spricht er S. 318 von einer kompletten Entartung des langen temporo-okzipitalen Assoziationsbündels, welche sich aus der Abtragung des Schläfelappens leicht (!) erkläre. Sehr auffallend ist dann der spätere Satz S. 322: "Unser Fall beweist zum ersten Male mit Sicherheit, dass mindestens ein sehr beträchtlicher Teil im Schläfelappen entspringt". Ein solcher Mangel an Kritik muss bei einem Forscher wie Edinger überraschen. Derselbe übersieht nämlich ganz die Möglichkeit, dass, wie Flechsig an entwicklungsgeschichtlichen Präparaten entdeckt hat, eine Umbeugung der für den Thalamus bestimmten Bündel existieren, dass eine Unterbrechung der Bahn selbst, nicht deren Rindenursprünge vorliegen könne, somit die wichtigste Voraussetzung für den Nachweis eines Assoziationssystems, des Anfangs und Endes eines Faserzugs in der Hirnrinde nicht gegeben sei.

1) Edinger, Geschichte eines Patienten, dem operativ der ganze Schläfelappen entfernt war, ein Beitrag zur Kenntnis der Verbindungen des Schläfelappens mit dem übrigen Gehirne. Deutsches Arch. f. klin. Med. 1902. S. 304-322. 
Ursprung und Verlauf der basalen Züge des unteren Längsbündels. 285

Auch Edinger's Schluss von der Degenerationsrichtung auf die Leitungsrichtung muss auf Grund späterer Erfahrungen (vgl. hierzu unsere Figg. 11 und 12) als hinfällig erkannt werden, indem dasselbe System bald nach dieser, bald nach jener Richtung degenerieren kann.

Es überrascht, wenn wir einen so ergebuisreichen Forscher wie Probst ${ }^{1}$ ) hartnäckig den Irrtum festhalten sehen, dass die Pars descendens eine Ausstrahlung des unteren Längsbündels geraden Wegs in den Schläfelappen bedente, dass ihm das Genu vollkommen entgangen sein könne, obschon er an Frontalschnitten, wie solche die Figg. 12, 13, 14, 15, 16 auf Taf. IV und 17 auf Taf. $V$ darbieten, den Zusammenhang der bei ihm wie bei uns von der Degeneration verschonten basalen Fászikel mit der längsgetruffenen, vom äusseren Knieböcker absteigenden Fasergruppe durch eine spitzwinkelige Beuge derselben vor Augen hatte. In einem zweiten von inm publizierten Falle ${ }^{2}$ ), in welchem durch einen Herd im Sebhügel das gesamte untere Längsbündel sekundär degeneriert war und dessen zerfallende Fasern durch Osmiumschwärze dentlich sichtbar und verfolgbar wurden, nötigten ihn die klaren, überzengenden Bilder $2 u$ dem Geständnis, dass Rindenausstrahlungen aus der Pars descendens und dem Knie nicht nachweisbar seien, und "doch", fährt Probst fort, „muss angenommen werden, dass die betreffenden Bündel auch in die Rinde einstrahlen". In die gesamte Rinde des Schläfe-, unteren Scheitel- und Hinterhauptslappens ergiesse sich ein Faserregen aus dem unteren Längsbündel, welches seine allmähliche Verjüngung nach dem Okzipital-, aber auch nach dem Temporalpol hin erkläre. Dies das einzige Argument, welches für diese unsichtbaren Einstrahlungen in die umliegenden Windungen spräche. Und doch, erregt es nicht unabweisbare Bedenken, dass trotz kompletter Entartung aller zur Rinde der Fissura calcarina ziebender Fasern des Längsbündels keine einzige, als schwarze Perlenschnur aus der geschlossenen Schicht heraustretend, in eine der Windungen der Hemisphärenkonvexität $z u$ verfolgen war. Während die sekundäre Degeneration aller Fasern in der geschlossenen Sagittalschicht des F.l.i. offen zutage lag, konnte Probst, der auf einzelne Faserabgänge sicher fahndete, keine einzige jener feinsten Fäserchen, welche gegen den Ventrikelrand hin anscheinend verliefen, mit Sicherheit nachweisen. In den Ebenen des vordersten

1) Probst, Zur Kenntnis der Grosshirnfaserung und der zerebralen Hemiplegie. Sitzungsber. d. Kaiserl. Akad. d. Wissensch., math.-nat. Kl. Bd. 112. Abt. 3. Dez. 1903.

2) Probst, Ueber die zentralen Sinnesbahnen und die Sinneszentren des menschlichen Gebirnes. Sitzungsber. d. Kaiserl. Akad. d. Wissensch., math.nat. Kl. Bd. 115. Abt. 3. März 1916. Vorgel. i. d. Sitz. am 11. Januar 1906. 
Schläfelappens, wie sie Fig. 3 vorführt, erklärt S. 49, I. c., der Autor ausdrücklich: "Nirgends ist aber auf den Schnitten eine Rindeneinstrahlung dieser Fasern zu sehen, weder in die Schläfewindungen, noch in den Gyrus fusiformis oder hippocampi oder in den Mandelkern". Es ist also nicht recht verständlich, warum sich Probst so entschieden gegen die Möglichkeit verwahrt, dass die Sehhügel-Rindenfasern, die gegen die Temporalspitze hin verlaufen, mit der Sebrinde in Verbindung stehen könnten. "Es muss daher (eine Begründung wird aber nicht gegeben) geschlossen werden", meint Probst, „da diese Fasern doch nicht plötzlich abbrechen können, dass ihre Rindenendigung mittels der Osmiumfärbung bei Berücksichtigung derselben Art der Metbodik und demselben Alter des Krankheitsherdes usw. nicht nachweisbar sind". Probst nimmt also Luflucht zu einer weit hergeholten Alternative, um der nächstliegenden Möglichkeit, dass die betreffenden Fasern im vorderen Schläfelappen umbögen und aufwärts zögen, und deshalb keine Rindenausstrahlungen zu sehen waren, auszuweichen.

La Salle Archambault) hat unter Pierre Marie's Leitung acht Gehirne mit ausgedehnten Erweichungsherden der hinteren Hemiphärenteile auf Frontalschnitten, welche nach Weigert-Pal gefärbt wurden, untersucht und seine Aufmerksamkeit insbesondere dem Faisceau longitudinal inférieur zugewendet. Er verweist S. 1055 auf einen Fall von ausgedehnter Erweichung, welcher "sectionne complètement toutes les connexions de la partie antérieure du lobe temporal" und doch konpte er nur eine leichte Entartung des inneren Anteils des horizontalen Abschnitts uachweisen. S. 1056 fährt dieser Autor fort: „Nous n'avons jamais constaté de dégénérescence du faisceau longitudinal inférieur ... à la suite ... de lésions de la partie antérieure du lobe temporal", unter der Voraussetzung, dass es sich nur um kortikale Läsionen handelt. Daher erklärt sich Archambault als Gegner der landläufigen Auffassung des F. l. i. als eines Assoziationssystems zwischen Hinterhaupt- and Schläfelappen. Für ihn ist dieser Faserzug vielmehr der Faisceau optique central, die zentrale Sehbahn, welche aus der oberen und äusseren Partie des Corpus geniculatum externum entspringt, in scbrägem Laufe herabsteigt, wie wir dies an unseren Präparaten anschaulich zu schildern in der Lage sein werden, um dann entlang der äusseren Wand des Schläfelappens nach hinten zu eilen. Dass er den basalen Teil des F. l. i. nicht für ein Assoziationssystem bält, geht auch aus seiner Einteilung der sagittalen Lager, indem er den

1) La Salle Archambault, Revue neurologique. 1905. Nr. 22. 
Ursprung und Verlauf der basalen Züge des unteren Längsbündels. 287

Faisceau optique central in das untere Drittel derselben verlegt, hervor. Unrichtig ist jedoch, wie unsere Figg. 13 und 14 beweisen, Archambault's Behauptung. dass der Projektionsfaserzug des äusseren Kniehöckers nicht rom Okzipitallappen aus sekundär degeneriere, da in unserem Falle im Gefolge einer Kalkarinaerweichung der gesamte Faisceau optique central degeneriert gefunden wurde, wie wir dies an den in den Figg. 11 und 12 reproduzierten Querschnittsbildern des linken äusseren Knieböckers nach einer vollständigen Entartung des unteren Längsbündels infolge einer auf die Kalkarinalippen beschränkten Erweichung konstatieren könnell.

Bei Starokotlitzky ${ }^{1}$ ) ist der F.l.i. Gegenstand der These. Wir erhalten daher eingehende Angahen über Ursprung, Verlauf und Endigung. Der Autor unterscheidet einen unteren und einen oberen Absclinitt des unteren Längsbündels. Während dieser seine Konfiguration an der lateralen Wand fortwäbrend ändert, "setzt der untere Teil unverändert seinen Lauf von hinten nach vorne fort, längs des unteren, äusseren Randes des Unterhorns. Auf diese Weise gelangt nun der untere Teil der lateralen Längsbündelplatte bis zum vorderen Gebiete des Schläfelappens, wo wir mil Sicherheit die Verzweigung und Endigung seiner Fasern konstatieren konnten." Die Ausstrahlungen desselben erfolgten in alle Windungen; zahlreiche Fasern gingen fortwährend nach Art des Federbartes von ihm nach vorne abwärts zur Rinde des G. hippocampi ab, auch eine grosse Zahl finde im Cornu Ammonis ihr Ende und ein Teil erstrecke sich sogar in den Uncus. Da der F.l.i., seiner Ansicht nach, aus allen okzipitalen Windungen hervorgehe, so ergibt sich der Schluss, dass die ganze untere Wand seiner Rinne und der untere Teil der vertikalen Wand ein Assoziationsbündel bilde, welcher die Rinde des Hinterhauptslappens mit der des Schläfelappens verbinde.

$\mathrm{Zu}$ einer solchen Auffassung des F.l.i. konnte Starokotlitzky nur gelangen, da er seinen Untersuchungen ausschliesslich Weigertpräparate, wenn auch verschiedener Schnittrichtung, so doch nur ausgewachsener normaler Gehirne zugrunde legte, an welchen die Frage, ob die von den Strata sagittalia nach der Rinde zu ziehenden Fasern aus diesen abgingen oder dieselben bloss traversierten, nicht zu entscheiden war. Entwicklungsgeschichtliche oder pathologische Selektionen sind allein geeignet, hierüber Aufklärung zu geben. Auf beiden Wegen - man betrachte nur unsere Figuren auf den beigefügten

1) Starokotlitzky, Das untere Längsbündel des mensohlichen Grosshirnes. Diss. Breslau 1903. 
Tafeln - führen zu dem übereinstimmenden Resultat, dass ein Abgang von Fasern aus der Bahn des F.1.i. nach den umliegenden Windungen nicht stattfinde. Zweitens begebt Starokotlitzky, der Autorität Dejerines folgend, den Fehler, den Fasciculus gyri hippocampi (siebe unsere Ausführungen hierüber weiter unten, sowie F. H. auf den Figg. 6, 7, 8, 9) mit dem F.l.i. zusammenzulegen, obgleich dessen Unabhängigkeit von letzterem mit den verschiedenen Methoden erweisbar ist. Dieser Irrtum erklärt auch die verwunderliche Angabe, dass ein zwischen Seh- und Hörsphäre postuliertes Assoziationssystem bis zu den Zellen des Ammonshorns mit freiem Auge verfolgbar wäre. Die charakteristische Umkehr und Rückwendung des F. l. i. im vorderen Schläfelappen entging Starokotlitzky deshalb, weil die durch die Schicht tretenden Fasern Ausstrahlungen vortäuschten.

Obersteiner ${ }^{1}$ ) schildert den Verlauf des unteren Längsbündels an einem porenzephalen Gehirn und konnte für die ventralen, schmäleren Teile die Bedeutung eines Assnziationssystems mindestens nicht widerlegen.

Redlich ${ }^{2}$, der wie wir ${ }^{3}$ ), die gesamten über das untere Längsbündel vorgebrachten Tatsachen, bei vergleichend anatomischer $\mathrm{Be}$ leuchtung zusammenfasst, gelangt zu dem Schlusse, dass nicht nur das Stratum sagittale externum in seinem grössten Teile unzweifelhaft Projektionsfasern enthalte, sondern, dass auch für den kleineren basalen Anteil, der im G. hippocampi und an der lateralen Umgrenzung des Unterhorns verläuft, die Bedeutung als Assoziationsbündel nicht erwiesen, ja nicht einmal wahrscheinlich sei. Hierza muss aber bemerkt werden, dass Redlich das Stratum sagittale externum nur in einen dorsalen und ventralen Anteil zerfallen lässt. Dieser ist mit dem basalen Zug des F.l.i. nicht identisch. An dem ventralen Abschnitt des F.l.i. muss eine mediale und eine laterale Fasergruppe unterscbieden werden. Die mediale kommt nicht vom Hinterhauptslappen; sie erscheint erst mit dem Auftreten des G. hippocampi, für dessen Stabkranz wir sie auch andernorts erklärt haben, wofür sie Redlich gleichfalls zu halten scheint. Für uns kommen nur die den Ventrikel lateral umgrenzenden Faszikel in Betracht, und deren Zugehörigkeit zu der dorsalen Faserschicht, als einer anatomischen Einheit ist hervorzuheben. Ich ver-

1) Obersteiner, Ein porenzephales Gehirn. Arbeiten a. d. neurol. Institut d. Wiener Univ. 1902. Bd. 8.

2) Redlich, Zur vergleichenden Anatomie der Assoziationssysteme des Gehirns der Säugetiere. Ebenda. 1905. Bd. 12.

3) Niesslv. Mayendorf, Arch. f. Psych. 1903. Bd. 37. 
misse bei Redlich ein Eingehen auf den Verlauf der untersten horizontalen Bündel, sowie eine Notiz wie über deren Ursprung and Ende; ferner geeignete Durchschnitte durch Tiergehirne, welche die Umbiegung derselben im vorderen Schläfelappen illustrieren oder widerlegen könnten.

Schaffer ${ }^{1}$ ) studierte die sekundären Degenerationen des F.l.i. an nach Weigert-Walters gefärbten Horizontalschnitten. Bei Besprechung der Grenzen der primären Läsion bemerkt er S. 1038. „Der ganze Okzipital- und Parietallappen ist intakt, allein die Temporalspitze, nämlich die erste Temporalwindung, sowie das Grenzgebiet zwischen Schläfen- und Stirnhirn (Area olfactoria) sind zerstört. Da der F.l.i. in diese Teile der Hemisphäre Fasem entsendet, so ist es wohl naheliegend, dass wir die Ursache der partiellen Degeneration des F.1.i. in der Zerstörung der Temporalspitze, ersten Schläfewindung und der basalen Frontallappenanteile erblicken. Freilich muss aber dann gefolgert werden, dass im F. l. i. a uch Fasern vom Temporallappen gegen den Okzipitallappen zu verlaufen, hier jedoch nicht endigen, sondern hinter der Spitze des Okzipitalhornes umbiegend wieder nach vorn bzw. innen zu, zum Präkuneus sich wenden. Es gibt daher einen Faserzug im Sagittallager des Temporookzipitallappens, welcher im Temporallappen, vielleicht auch im basalen Frontallappen entspringend und die äusserste Schicht des F. l.i. bildend, im Marke des Okzipitallappens um die hintere Spitze des Okzipitalhornes eine scharfe Biegung macht und im Präkuneus endet. "Dieser Faserzug ist ein temporo. präokzipitales Assoziationsbündel. Es dürften also im F.l.i. s. Stratum sagitrale okzipitotemporale Assoziationsfasern in doppelter Richtung verlaufen; einmal gehen Fasern vom Okzipitallappen gegen den Temporallappen zu und zweitens ziehen Fasern vom Schläfelappen gegen den Präkuneus. Letzteres Kontingent bildet die äusserste Schicht des F. I. i. Ein dritter Bestandteil dieses Bündels repräsentiert Projektionsfasern, welche gemäss den Untersuchungen Probst's von den drei Okzipitalwindungen entspringend im Pulvinar, im äusseren Kern des Sehbügels, hauptsächlich aber im äusseren Kniehöcker ihr Ende finden". Die hier vollständig wiedergegebenen Ausführungen enthalten fast ausschliesslich Argumentationen, welche auf den Schultern erst zu beweisender Behauptungen stehen. Schaffer, welcher Dejerine's Ansichten über die Zusammenhänge des F.l.i. rücklıaltlos teilt, fundiert seine Deutung der partiellen Entartung des F. l. i, auf die von jenem

1) Schaffer, Ein Fall von ausgodehnter Meningitis syphilitica der Hirnkonvexität und Basis. Neurol. Zentralbl. 1904. Nr. 22. 
postulierte Tatsache, dass das Längsbündel mit der Temporallappenspitze, der ersten Schläfewindung und der basalen Frontallappenrinde in Verbindung stehe. Wie wir unten aber sehen werden, ist diese Hypothese, nach dem der Nachweis einer Umbiegung des F.l.i. im vorderen Schläfelappen, und des absteigenden Verlaufsstücks aus dem äusseren Kniehöcker, ferner die Intaktheit des F.l.i. bei vollständiger Zerstörung der vorderen Schläfelappenrinde, ferner der nach degenerativem Faserverlust durch überzeugenden Augenschein mögliche Ausschluss jeder Einstrahlungen in die erste Schläfewindung gelungen ist, vollkommen unhaltbar. Die weitere Folgerung, welche Schaffer aus dieser bereits abgetanen Annahme, wobl aber im Hinblick auf die Degenerationserscheinungen seiner Horizontalschnitte zieht, weil eine feine Lichtung sich in das Mark eines Windungsläppchens verfolgen liess, welchen er als Präkuneus ansieht, steht durchaus in der Luft. Der Horizontalschnitt, welcher beweisen soll, ist durch die Mitte des Sehhügels geführt (siehe Fig. 5). Ein Präparat, welches den basalen Anteil des F. I. i. in seiner Beschaffenheit vor Augen führte, ist weder geschildert noch abgebildet. Auch eine verwertbare Beschreibung der hier wichtigen subkortikalen Ganglien, wie des äusseren Kuiehöckers mangelt. Dass die streifenförmigen Lichtungen im Mark des Hinterhauptlappens von einer sekundären Degeneration des F.l. i. herrühren, ist immerhin möglich, aber das Unterfangen, die Degenerationen anf eine Erkrankung der Schläfelappenrinde zurückzuführen, muss ein durchaus willkürliches und verfehltes genannt werden, da der F. l. i. offenbar in seinem basal horizontalen Anteil durch den Erkrankungsherd primär unterbrochen wurde. Eine Reihe von Horizontal- besser noch von Sagittalschnitten hätte hier Aufschluss gebracht. Wir werden unten an der Hand unzweideutiger Weigertpräparate ein Eingehen des basalen Schenkels in die vorderste jener Windungen, deren Rinde mit einem Viq. d'Azyr'schen Streifen versehen ist, wahmehmen können. Es ist nun insbesondere bei Heranziehung von Weigertpräparaten mit analogen pathologischen Verbältnissen, aber anderer Schnittrichtung mit Sicherbeit festzustellen, dass das kortikale Einmündungsgebiet des basalen F. l. i. der vordere G. lingualis ist. Wir wissen überdies, dass nur die Lippen der Fissura calcarina den kortikalen Varkstreifen in charakteristiscb typischer Ausprägung tragen. Da, wie Fig. 5 zeigt, die mit Prc. bezeichnete Windung den kortikalen Kalkarinatypus besitzt, der Präkuneus eines solchen aber entbehrt, so kann es sich bei der fraglichen Windung nur um einen Zipfel des G. lingualis handeln. Denn nur diese Windung schiebt sich bekanntlich von den beiden Kalkarinalippen am weitesten vor. Was endlich $\mathrm{Schaffer}$ über den Ursprung der Projektionsbündel 
des F. I. i. im Hinterhauptslappen auf Grund eines Falles von Probst ${ }^{1}$ ) vorbringt, dass dieselben aus der Rinde der drei lateralen Okzipitalwindungen hervorgingen, so hält dies ebeufalls der Kritik nicht stand, da in Probst's Falle nicht allein die Rinde, sondern auch das Marklager in der Tiefe von der Erkrankung vernichtet worden war, also sämtliche, die sagittalen und ventralen Bündel des F.1.i, auf ihrem Wege von ihren Ausgangspunkten in der medialen Hinterhauptsrinde abgeschnitten worden waren.

Hösel2) fand an dem Gehirn eines ausgetragenen Kindes, welches vier Stunden nach der Geburt gelebt hat, zahlreiche markhaltige Nervenfasern im dorsalen lateralen, in geringerer Anzahl in seinem ventralen Anteil, während die zentralen Teile nur spärliche Fasern enthielten. Wie an den Figuren 12, 13, 14, 15 ersichtlich, ist der F. l. i. (das Stratum sagittale externum, die primäre Sehstrahlung Flechsig's) zu einem Teile markumbüllt. Es ist nicht allein die ventrale Lage markbekleidet, sondern auch die dorsale, welche die laterale Ventrikelwand bildet. Das Endigungsgebiet dieses kortikopetalen Systems ist die Unterlippe der Fissura calcarina. Frei von Fasern war die Oberlippe, alle Okzipitalwindungen bis zum Okzipitalpol, der ganze Kuneus. Soweit man sich nach dieser Schilderung und den schematischen Darsteliungen ein Urteil bilden kann, ist der gesamte oder grüsste Teil des F.l. i. markhaltig und nur dem letzten Stück der dorsalen Bündel, welche in den Pol und die Unterlippe strahlen, fehlen die Markscheiden. Ich halte den Schluss daher nicht für gerechtfertigt, dass das ganze vorliegende Stratum externum nach vollendeter Markreifung nur in der Rinde des $G$. lingualis endige. Wichtig ist für uns die Tatsache, dass die basalen Züge des F. I. i. in ihrer Markreifung mit den Bündeln für den $G$. lingualis und der dorsolateralen Strahlung vom äusseren Kniehöcker gleichen Schritt halten, dass somit eine leitende Beziehung der horizontalen basalen Faserschicht zu der Oberlippe und zu dem dorsomedialen Kniehöcker nicht existiert. Ferner sehen wir auf das Klarste, dass aus der basalen Schicht des F.I. i. keine Fasern in den Schläfelappen oder sonst wohin ausstrahlen, dieselbe, wie Hösel mit Recht hervorhebt, kein Assoziationssystem zwischen Hinterhaupts- und Schläfelappen sein kann. Endlich trennt Hösel ganz richtig den medialsten, im G. hippocampi laufenden quergetroffenen Faserzug, dessen Zugehörig-

1) Probst, Zur Kenntnis des Sagittalmarks und der Balkenfasern des Hinterhauptlappens. Jahrb. f. Psych. 1901.

2) Hösel, Ueber die Markreifung der sogenannten Körperfüblssphäro und der Riech- und Sehstrahlung des Menschen. Arch. f. Psych, Bd. 39. H.1. 
keit zur Rinde des G. hippocampi so naheliegt, und der kaum anders als Stabkranz dieser Windung gedeutet werden kann von dem ventrallateralen, unserem basalen F. I.i. ab. Auf den Fig. 14, 15, 16, 17 ist zu sehen, dass es sich um zwei verschiedene Leitungssysteme handelt.

Weber ${ }^{1}$ ) bält, ausgehend von dem Studium sekundärer Degenerationen in einem Falle von Erweichung der Kalkarinagegend, dafür, dass der F.l.i. aus Projektionsfasern und Assoziationsfasern sich zusammensetze. Mehr nach vorne zu schieden sich beide Systeme, die Projektionsfasern stiegen empor und nähmen die obere Etage ein, um zum C. gen. ext., Pulv. usw. zu gelangen, die Assoziationsfasern blieben in der unteren Schicbt und begäben sich zum Schläfelappen. Diese Schlüsse werden aus Befunden gezogen, die der Autor an einer Serie nach Weigert-Pal behandelter Frontalschnitte erhoben hat. Er meinte, diesen "entnelımen zu können, dass, da die oberen Partien der Radiatio thalamica sowie des Fasciculus longitudinalis inferior frei von sekundären Degenerationen waren, diese Faseranteile mit dem Cun., Lob. ling. u. $\mathrm{O}_{2}$ nichts zu tun hätten. Die beigegebenen Abbildungen sind Federskizzen und geben keine Vorstellung von dem tatsächlichen Verhalten und der Lage der 'entmarkten Stellen. Weber bestreitet die von mir bereits im 37. Band des Archivs für Psychiatrie bei meiner ersten Schilderung des Verlaufs des unteren Längsbündels vertretene, durch die naturgetrene Wiedergabe eines Sagittalschnittes aus dem Gehirn eines 9 Wochen alten Knaben (siehe Fig. 3 auf Taf. VIII) bewiesene Anschauung, dass der basale Teil des F.l.i. in gerader Richtung von hinten nach vorne streiche und, im vorderen Schläfelappen umkehre, aufsteige und sich mit dem Gesamtkumplex des F. l. i. vereinige. Gründe gegen die Richtigkeit meiner Angabe werden nicht vorgebracht. Weber's Irrtum erklärt sich aus dem Unvermögen, die basale Umkehr an Frontalschnitten zu sehen. Demselben Schicksal verfielen alle jene, welche an derselben Schnittrichtung die Verlaufsverhältnisse des F.1.i. studieren wollten.

Adolph Meyer ${ }^{2}$ ) gelangt in einer bündigen, aber klaren Studie zu dem Ergebnis, dass der F. I. i. ein kompaktes Bündel sei, welches aus den Ganglien des äussereu Kniehöckers entspringe und nit einem Bogen im vordersten Temporallappen, unweit des Poles, in die Windungen der Fiss. calc. nach hinten sich begebe.

1) Weber, Note sur la dégénérescence secondaire consécutive à un foyer etc. Arohives de Neurologie. 1905.

2) Adolpb Meyer, The connections of the occipital lobes etc. Transactions of the American Physicians. 1907. 
van Valkenburg beschäftigt sich in zwei Arbeiten mit dem unteren Längsbündel. In der deutsch geschriebenen ${ }^{1}$ ) lag ein Erweichungsherd vor, welcher das rechte Corpus geniculatum externum gänzlich, teils primär, teils sekundär, zur Degeneration brachte. Die in französischer Sprache abgefasste Mitteilung ${ }^{2}$ ) referiert über eine sehr umfangreiche Malazie, welche die linke Grosshirnhälfte zum grössten Teil, und zwar den Stirulappen, die Zentralwindungen, den Scheitellappen in eine Zyste verwandelt hatte (siehe Fig. 1, S. 2). Nur die erste Pablikation ist für unser Thema von Bedeutung. S. 333 muss van Valkenburg zugeben, dass das untere Längsbündel als entartet $z \mathfrak{a}$ betrachten, dass es höchstwahrscheinlich in seiner ganzen Breite degeneriert sei, denn es würde wenigstens lateral wie medial von Fasern begrenzt, welche, wie der Vergleich mit normalen Präparaten lehrt, in das ihm zukommende Areal nicht gehören, und die genikulo-kortikale Strahlung in ihrem okzipitalen Abschnitt sich auf den F.1. i. beschränkte. „Ein Bestandteil aus Assoziationsfasern aus $\mathrm{T}_{1}$ oder Gyr. supramarginalis, welche teilweise der Sitz des Herdes waren, ist nicht von vorneherein auszuschliessen."

In der zweiten Abhandlung, welche einen Fall analysiert, bei welchem trotz der umfangreichen Läsion der äussere Kniehöcker mit dem F.l. i. vollständig erhalten geblieben waren, meint Verf. S. 14, aus seiner Darstellung gehe hervor, dass die Faserung vom Knieböcker zum Hinterhauptslappen eine sehr leichte Krümmung nach vorne (une [plus legère] courbure en avant) aufweise, wie Flechsig und ich auf Grund entwicklungsgeschichtlicher Präparate vermuteten (comme la myelogénèse l'avait déjà fait présumer); c'est, fäbrt van Valkenburg triumphierend fort, „ce que la dégénération secondaire n'avait pu confirmer jusqu'ici".

Wir würden uns dieser Uebereinstimmung sehr freuen, wenn wir nicht den Verdacht hätten, dass der Autor mit plus legère courbure das von Flechsig und mir mit der myelogenetischen Methode nachgewiesene Knie des F.l.i., welche er auf seinen Frontalschnitten nicht deutlich sehen konnte, bei der zitierten Angabe wirklich im Auge gehabt hat.

1) van Valkenburg, Zur Anatomie der Projektions- und Balkenstrahlung des Hinterhauptslappens sowie des Zingulums. Monatsschr. f. Psych. u. Nourol. Bd. 24. H. 4.

2) van Valkenburg, Contribution à l'étude de la constitution de la substance blanche temporo-occipitale de l'homme. Psych. en Neurologische Bladen. 1911. Nr. 4 u. 5. 
In unserem Misstrauen werden wir um so mehr bestärkt, als van Valkenburg S. 22 direkt erklärt: „La partie temporale antérieure au contraire jusqu'ici a été très insuffisamment, analysée. Aussi notre cas ne peut-il pas résoudre définitevement le problème de sa constitution".

Auch verstehen wir ihn nicht, wenn er voll Genugtuung sich rühmt, diese hypothetische Krümmung nun mit der Methode der sekundären Degeneration festgestellt zu haben, da doch in seinem Falle weder der F.l. i. noch dessen nächste Umgebung entartet war, wodurch sich der intakte Faserzug schärfer als im normalen Präparat hätte abheben können.

Ebensowenig begründet klingt seine Annahme, dass sich sicher (il est certain que ...) Assoziationsfasern dem F. l. i. zugesellen. van Valkenburg glaubt einen Teil des Fasciculus uncinatus im F.l.i. verfolgen zu können, obgleich er $\mathrm{S} .21$ eingesteht, diesen medialen Anteil des Faisceau uncinatus im Schläfelappenmark selbst nicht verfolgen zu können (il est impossible de suivre les fibres aussitôt qu'elles de sont enfoncées dans la masse blanche temporale ...). "Andere Assoziationssysteme begleiteten zweifellos den F.l. i. wahrscheinlich (probablement) seinem ganzen Verlauf entlang." Auch diese Bemerkung beweist, dass van Valkenburg eine klare Vorstellung von der $\mathrm{Zu}$ sammensetzung des F. l.i. nicht hatte.

Dagegen erkennen wir es als Fortschritt an, dass Valkenburg die mediale Hälfte des ventralen Sagittalstratums vom F. l. i. trennt und als eigenes Bündel „Faisceau juxta-amygdalien" hezeichnet. Seine Annahme, dass derselbe-in der Spitze des Schläfelappens entspringe, ist jedoch unrichtig, wie wir an unseren Präparaten einwandfrei seben werden, an welchen die Spitze zerstört war und das Bündel F H unversehrt sich darbot. Dass der Mandelkern sein Ursprungsort nicht sein könne, muss er aus seinem eigenen Fall mit $Z_{\text {wang }}$ folgern.

Tsuchida ${ }^{1}$ ) untersuchte ein porenzephalisches Gehirn, dessen linker Okzipitallappen sowobl durch die vorhandene Zyste als durch die Folgen einer zu therapeutischem $Z$ wecke vorgenommenen Operation in grossem Umfange zerstört war. "In der Hauptsache erfuhr der innere, dem Hinterhorn anliegende Teil des Okzipitalmarks, also die Markanteile und Markzungen, der G. fusiformis und der Lobulus lingualis die meisten Unterbrechungen durch die Ausdehnung des porenzephalischen Herdes"... (S. 222): „das Stratum sagittale ex-

1) Tsuchida, Ein Beitrag zur Anatomie der Sehstrahlungen beim Menschen. Arch. f. Psych. Bd. 42. 
ternum (unteres Längsbündel, Fasc. long. inf.). Dieses Stratum ist in seiner Verlaufsstrecke von der Okzipitalspitze an weit über die Ebenen des äusseren Ḱniehöckers hinaus bis zu jenen Ebenen, wo die Amygdala in die Schnittfläche fällt bzw. wo dieses Bündel sich aufsplittert, in hochgradiger Weise sekundär degeneriert." ... Ferner S. 238: „Das Corpus gen. ext. war ja in unserem Falle völlig entartet"... An anderer Stelle bezeichnet er dasselbe als "total vernichtet" (S. 241). Iie Abbildungen, leider nur Zeichnungen von frontal geschuittenen Weigertpraparaten, beweisen, was Tsuchida gerade in Abrede stellt, dass der F.l.i. als geschlossenes Bündel aus dem C. g. e. entspringt und als solches okzipitalwärts zieht (siehe die Figg. 1 und 2 auf Taf. VII). Abgänge sekundär degenerierter Fasern in das Mark der umliegenden Windungen sind ganz richtig nirgends eingezeichnet. Wer daher, ohne den Text gelesen zu haben, nur die Figuren betrachtet, muss zur Ueberzeugung gelangen, dass das C. g. e. der einzige Ursprungsort des F.l. i, sei.

Bei der Beschreibung des F.l.i. bemerkt aber der Autor: "Auf den ersten Blick erschien dieses Gebilde (das F.l. i.) vollständig vernichtet, bei näherer Betrachtung liess sich jedoch in diesem Stratum noch eine ganz stattliche Anzahl von Fasern entdecken. Freilich präsentieren sich diese verschont gebliebenen Fasern als solche auffallend k]einen Kalibers, jedenfalls waren Bündel mit derberem Faserkaliber im okzipitalen Abschnitte des Stratums nirgends zu sehen. Im frontalen Segmente des Strat. sag. ext. dagegen waren derbkalibrige Markfasern wieder in normaler Zahl und Grösse anzutreffen; die im okzipitalen Segment im nämlichen Stratum erhalten gebliebenen feinkalibrigen Fasern erschienen hier an Frontalschnitten meist schräg oder längs getroffen, sei es als mediolateral oder als dorsolateral ziehende Bündel oder solcbe, die von der dorsalen Richtung nach der ventralen quer gelegenen Schicht übergingen."

Diese "anatomischei Resultate" erscheinen Tsuchida klar genug, um in der Streitfrage über die Bedeutung der im Strat. sag. ext. verlaufenden Fasern, d. h. ob diese Assoziations- oder Projektionsbündeln zuzurechnen seien, "ein bestimmtes Urteil" auszusprecheo:

"Diejenigen Fasern im Strat. sag. ext., welche ein derbes Kaliber zeigen und an Frontalschnitten quergetroffen erscheinen, sind in ihrer Mehrzahl Projektionsfasern, und zwar vorwiegend solche, welche dem C. g. e. entstammen." . . „Die in unserem Falle von der sekundären Degeneration verschont gebliebenen feinkalibrigen Fasern im Strat. sag. ext. dagegen stellen, sofern sie in einer anderen Richtung als die ersterwähnten ziehen, fast lauter Assoziations- und Balkenfasern dar." Das 
Schlussergebnis lautet daher, der F.1.i. besteht aus Projektions- und Assoziationsfasern.

Ich konnte es mir nicht versagen, den Gang der Beweisführung unverkürzt wiederzugeben, um durch dieses Beispiel die allenthalben krampfhaft festgehaltene Tendenz, die Tradition von dem assoziativen Charakter des F.l.i. zu retten, zu beleuchten. Deshalb, weil in dem entmarkten Stratum sagittale externum "eine stattliche Anzahl" von "feinkalibrigen" Fasern sich finden, von welchem der Verfasser nicht anzugeben weiss, von wo sie kommen und wohin sie gehen, deshalb müssen die Fasern Balken- oder Assoziationsfasern sein. Schliesslich wird der Balkenfasern auch vergessen und das Endurteil lautet: Der F. l. i. konstituiert sich aus Projektions- und Assoziationsfasern.

Bereits ein Anblick der wenigen reproduzierten Präparate gibt uns jedoch eine ganz andere Erklärung für das Vorhandeosein der zurückgebliebenen normalen Fasern an die Hand, als sie Tsuchida geben zu müssen glaubte. Wir gewahren nämlich auf Taf. VIII, Fig. 4, dass keineswegs die ganze Area striata, in welcher der F.1.i. endigt, destruiert ist, ebensowenig ist, wie der Autor versichert, das sekundär degenerierte Stratum externum von starkkalibrigen Fasern frei. Dagegen ist die Oberlippe der Fissura calc., hier mit P. cum bezeichnet, nicht nur selbst vollkommen intakt, sondern man sieht auch die. über dem Ventrikel zu Gruppen gesammelten Markfasern in diese Oberlippe hiueinziehen. Dieselben entspringen aber aus dem dorsomedialen Anteil des äusseren Knieböckers, und wirklich zeigt uns die, wenn auch durchaus schematische Skizze des C. g. e. auf Taf. VII, Fig. 1a, dass die dorsomediale Einstrahlung des F.l.i. in denselben intakt war, nur weist sie Tsuchida, hier ebenfalls im Banne des traditionellen Dogmas stehend, dem Strat. sag. int. zu. Dass ein Zusammenhang zwischen C. g. e. und Strat. sag. int. jedoch nie und nimmer existiere, beweist der in unserer in Fig. 12 veranschaulichte Degenerationsbefund auf das schlagendste. Da das faserleere Areal von dem es umgebenden Fasergerüste stark eingeengt ist, ist es immerhin möglich, dass einzelne feinkalibrige Fasern des Stratum in ternum auf dem Territorium der äusseren Schicht verschoben waren. Jedenfalls ist das Gros der stattlichen Anzahl normaler Elemente im Stratum externum auf von der Erkrankung unberührte Reste des dorsalen F.l.i. zurückzuführen. Wie man sieht, lässt sich nicht nur nicht die assoziative Natur der fraglichen Fasern durch keine plausible Vermutung irgendwie stützen, sondern ihr projektiver Charakter strikte beweisen.

Wenn Tsuchida die sekundäre Degeneration des Stratum sag. ext. über den Kniehöcker hinaus bis zu jenen Ebenen, wo die Amygdala in 
die Schnittfäche fältt, verfolgen konnte, so ist dies kein Gegenbeweis dafür, dass der F. 1. i. nicht aus dem C. g. e. entspringt, und ein Beweis, dass er sich im vorderen Temporallappen aufsplittern müsse, da, wie wir unten sehen werden, der F.1.i. weit im Schläfelappen nach vorne zieht, um sich dann, knieförmig umkehrend, nach rückwärts und aufwärts zu wenden.

Fingehend wird die Frage nach der Biegung der basalen Fasern des F. 1.i. im vorderen Schläfelappen von Herrn Curt Löwenstein ${ }^{1}$ ) erörtert. Dieser Autor glaubt, die von H. Sachs zugestandene Biegung wohl zu kennen, hält dieselbe jedoch für eine nur "scheinbare, welche durch die Schnittfülırung und das Zusammenstossen verschiedener Fasern vorgetäuscht werde". Er schmeichelt sich ferner, einen Beweis erbracht zu haben, dass "solche vom Thalamus zur Seliphäre ziehende und im Temporallappen umbiegende Fasern nicht vorhanden sein können".

Der Beweis liege in dem Befund des ersten von ibm geschilderten Falles (Bo., S. 275/76). In diesem hat eine Geschwulst (!) den vorderen und mittleren rechten Schläfenlappen mit Verschonung der vordersten und obersten Partie eingenommen, soweit man sich ein Urteil über die wirklichen Verhältnisse nach dem Linienschema der Fig. 10 bilden darf. Untersucht wurden Frontalschnitte, die teils nach Weigert-Pal, teils mit Karmin gefärbt wurden. Die letztere Methode wird gerühmt und als besonders brauchbar (!) bezeichnet.

Der Verfasser behauptet Intaktheit der in die primären optischen Zentren ziehenden Fasern, Intaktheit ihrer zelligen Elemente, mithin könne es durch den vorderen Schläfelappen ziehende und nach oben umbiegende Fasern nicht geben, denn diese müssten sekundär degeneriert sein, wären sie kortikofugal; wären sie aber kortikopetal, dann müsste in den Ganglien des Hirnstammes retrograde Degeneration nachzuweisen sein, weder das eine noch das andere sei aber der Fall gewesen. Ferner sei die von dem Tumor okzipitalwärts verlaufende Faserung "diffus" degeneriert gewesen, sowohl in dem inneren als in äusseren Stratum seien Entartungserscheinungen aufgetreten, die entarteten Fasern erreichten nicht insgesamt die Rinde des Okzipitallappens.

S. 276 meint der Autor: "Unter Berücksichtigung all dieser Tatsachen können wir sagen, dass es sich bei diesen ausgefallenen Fasern $(\beta)$ auch nicht um kortikopetale optische Projektionsfasern, also, da wir oben auch kortikofugale Elemente ausgeschlossen haben, über-

1) Curt Löwenstein, Zur Kenntnis der Faserung des Hinterhauptsund Schläfelappens usw. Wiesbaden 1911. Bergmann. 
haupt nicht um optische Projektionsfasern handeln kann (?). Daher müssen wir diese Fasern als Assoziationsfasem ansprechen." Wir können aber auch sagen: „optischeProjektionsfasera, die durch den in unserem Fall defekten Teil des Temporallappens mit Hilfe einer Biegung (Flechsig) ziehen, existieren überhaupt nicht".

Der Autor, welcher hyperkritisch an die Verwertung und Folgerungen der Befunde Anderer kaum je erfüllbare Forderungen stellt, fällt einem groben methodologischen Irrtum anheim, welcher nur in einer beschränkten Erfabrung auf dem Gebiete der Untersuchungen sekundär entarteter Markfasern seinen Grund haben kann. Allem Anscheine nach ist es ihm nicht bekannt, dass Geschwülste zur Verfolgung des Verlaufs entarteter Markbahnen nicht verwendet werden dürfen. Neubildungen pflegen nicht die Ursprungskerne bestimmter Fasersysteme oder diese selbst zu zerstören, sondern nur zu verdrängen. So sehen wir z. B. nie von einer Geschwulst eine kompakte strangförmige Degeneration ausgehen, sondern stets eine diffuse Veränderung des benachbarten Gewebes, welche von Löwenstein selbst zutreffend hervorgehoben wird. Fs handelt sich, wie dies an den unscharf begrenzten Lichtungen des Marklagers ersichtlich ist, um Kompressionswirkungen nach mehrfacher Richtung. Es können daher in solchen Fällen Entartungserscheinungen an den Ursprungsganglien der gedrückten Faserleitungen fehlen; wenn solche aber auch vorhanden wären, so würden sie doch derart beschaffen sein, dass sie, nur mit der Karminmethode untersucht, sich sicher dem Nachweis entzögen. Wenu es ein wesentlicher Unterschied ist, ob einem Projektionsfaserzug Assoziationsfasern beigemiscbt sind oder nicht, wie will dies Löwenstein mit der Weigert-Palmethode entscheiden, welche die sekundären Degenerationen nur kompakter Stränge zur Anschanung bringt? Aber selbst, wenn er eine Methode zur Anwendung gebracht bätte, welche einzelne isolierte, degenerierte Fasern darzustellen vermag, wie etwa die Marchifärbung, so wäre er nie und nimmer imstande, Anfang und Ende dieser Faser zu bestimmen, wenn sie nicht ganz kurz und ihr vollständiger Verlauf im Schnittbilde zu überblicken wäre, und dies müsste doch für die Qualifikation dieser Faser als Assoziationsfaser gefordert werden. Aus welch' vagen Tatsachen glaubt aber Löwenstein den anatomisch-assoziativen Charakter der fraglichen Bündel erschliessen zu können! Ebenso wie Probst vermeint er, aus der Verjüngung des Strat. sag. ext. nach der Schläfelappenspitze zu, den fortlaufenden Abgang von Fasern in die Rinde des Schläfelappens ableiten zu müssen, ohne zu bedenken, dass die Verkleinerung der Schicht ebensowohl aus 
Ursprung und Verlauf der basalen Züge des unteren Längsbündels. 299

dem kontinuierlichen Abgang von Fasern in den Sehhügel erklärbar wäre.

In demselben Jahre, in welchem Löwenstein seinen Beitrag vor die Oeffentlichkeit brachte, wählte Mlle Marie Charogorodsky dasselbe Thema zum Gegenstand einer Inauguraldissertation ${ }^{1}$ ). Die anatomische Untersuchung eines Falles von zystischer Erweichung des linken hinteren Parietallappens. in der Höhe der zweiten Hinterhauptswindung, welcher intra vitam das Symptom der Alexie geboten batte und in dem ein operativer Eingriff an genannter Stelle ausgeführt worden war, hatte mit der Schwierigkeit zu kämpfen, dass die Grenzen der alten ursprünglichen Malazie infolge jüngerer Zerstörungen, die dasselbe Gebiet trafen, nicbt mehr genau bestimmbar waren. Jedoch liess sich an Frontalschnitten erkenuen, dass der alte Herd den Cuneus, das Marklager in der Ungebung des Hinterhauptspoles, sowie einen Teil der zweiten Okzipitalwindung vernichtet hatte. Das Gebirn wurde an einer fortlaufenden Reihe von Frontalschnitten untersucht, die nach WeigertPal gefärbt wurden. Das ganze untere Längsbündel, somit auch sein basaler Anteil, wurde sekundär degeneriert, der linke äussere Kniehöcker, mit dem rechten verglichen, bedeutend verkleinert gefunden. Den basalen Traktus erklärt die Verfasserin, ihrem Lehrer Professor Weber folgend, für ein die Spitze des Hinterhauptslappens mit derjenigen des Schläfelappens verbindendes Assoziationssystem. Als einzigen Grund vermag sie allerdings nur anzuführen, dass die sekundäre Degeneration desselben von hinten nach vorne an Intensität sukzessive abnehme, es müsste daher die entartete Zone ununterbrochen Fasern abgeben. "Si F. l.i. se rendait à la pointe temporale", betont Mlle Charogorodsky S. 15, „pour revenir à c. g. e. le contraire devrait avoir lieu, puisque nous rencontrerions ici lesfibres deux fois, a l'aller et au retour". Dieser Schluss aus dem Vordersatz ist aber nicht die unbedingte, $z$ wingende Folge, denn die Faserabgabe braucht ja nicht an die Rinde zu erfolgen, sondern kann sich ja auch nach den Stammganglien zu vollzieben. Charogorodsky fällt es sogar selbst auf: „à mesure que l'on se rapprocbe de c. g. e. dégénérescence de F.l.i. devient moins compacte", und dennoch erwägt sie mit keinem Worte die Möglichkeit, dass die Faserabgänge in den äusseren Kniehöcker die Verkleinerung des Degenerationsareals vollkommen erklären könnten. Es ziehen Fasern aus dem horizontalen Schenkel kontinuierlich empor und die rückläufigen Bündel können

1) Charogorodsky, Note sur la dégénérescence secondaire consécu. tive à un fojer de ramollissement du lobe occipital. Thèse. Genève 1911. 
nicht mehr in einer Verbreiterung der ersteren, sondern nur an dem vertikalen Abschnitt sichtbar werden. Es bleibt ferner die Tatsache unbeachtet, dass aus dem kompakten Strang des F.l.i. an der okzipitalen Basis eine fächerartig sich entfaltende Entbündelung, ein Auseinandertreten der Fasern an der temporo-parietalen Wand stattfindet, und dass ein Faszikel von oben her in das C. g. e. eintritt. Alle diese Verbältnisse sind aber bei Anwendung der frontalen Schnittrichtung nur unvollkommen und bruchstücksweise erkennbar.

Im folgenden Jahre beschäftigt sich eine Doktorarbeit aus der psychiatrischen Klinik der Universität Genf (Prof. R. Weber) mit demselben Gegenstand ${ }^{1}$ ). Es handelt sich um zwei kleine, unweit voneinander entfernte Herde, welche die Sagittalstrata des Hinterhauptslappens durchbrachen. Bei den Schlüssen, welche Ferrière aus seinen Befunden zieht, tritt er ganz in die Fussstapfen seiner Vorgänger. Auch nach ihm enthält der F.l.i, welcher un faisceau de projection geniculo-calcarin sei, nebenbei Assoziationsfasern, ohne dass er ihren Anfang und ihr Ende anzugeben, also ihre Eigenschaft als solche zu beweisen vermöchte. Seine Gründe sind nichts weiter als vage Möglichkeiten. So sieht er, 1. c. S. 27, die traversierenden Fasern, welche hindurchträten, in Schnittebenen durch das untere Längsbündel nicht hindurcbträten, sonderu sich ihm anzuschliessen scheinen, als Belege für den assoziativen Charakter einzelner Fasern an, welche von der Wegstrecke der sagittalen Lager abzweigen und in die Rinde strahlen sollten. "Voilà doncencore une raison (?) pour que ce faisceau ne soit pas dépourou de fibres d'association".

Seinem Lehrer Weber folgend, nimmt Ferrière an, dass Assoziationsfasern in der unteren Etage des F. l. i. zu einem Strang geschlossen, im Schläfelappen sich erschöpfen. Die von Flechsig entdeckte und von mir bestätigte Rückwärtswendung, dass der F. l.i. in der Nähe des Temporalpoles umkebre, um dann mit dem äusseren Kniehöcker in Konnex zu treten, glaubt der Autor entschieden ablehnen zu können: „En effet, nous en avons vu la dégénerescence s'épuiser peu à peu, à mésure que nous avancions vers le pôle temporal: cela ne pourrait être le cas si cette courbure existait réellement; la zone blanche devrait au contraire rester compacte et même augmenter de volume à un moment donné". Seltsamerweise dieselbe paradoxe Logik, wie wir sie bei Probst, Löwenstein, Charagorodsky antrafen, und doch zeichnet Ferrière auf seinem Linienschema Fig. 11 (rot liniiert)

1) Lonis Ferrière, Du Parcours des faisceaux sagittaux du lobe occipital. Thèse. Genève 1912. 
Ursprung und Verlauf der basalen Züge des unteren Längsbündels. 301

den Gang des horizontaleu Schenkels des F.l.i., an der Spitze des Schlüfelappens heraufbiegend, ganz richtig.

1913 erschien die inhaltsreiche Arbeit des leider zu früh dahingegangenen v. Stauffenberg über Seelenblindheit ${ }^{1}$ ). In dieser wird eingehend von dem unteren Lüngsbündel gehandelt und sein basaler Teil von der Warte der Degenerationsergebnisse, sechs mit der WeigertPalmethode genau untersuchter Hemisphären, deren Hinterhauptslappen durch Malazien zerstört war, kritisch betrachtet. „Die von Flechsig; Niessl, Hösel, Meyer behauptete Ausbiegung der Sehbahn des Stratum externum in den Temporallappen, die von v. Monakow, Löwenstein und Edinger bestritten wird, scheint mir $z$ war nicht in der Form den Tatsachen zu entsprechen, wie jene Autoren sie annehmen, aber ich glaube doch, dass unser Fall T. ihnen soweit recht gibt, als hier schon wenige Schnitte kaudal von dem zerstörten Ausgangspunkt die Degeneration bis in die ventrale Etage des Sagittalstratums hinunterreicht, also die nach hinten ziehenden Fasern vom Thalamus und Corpus genic. externum jedenfalls ziemlich steil nach ábwärts gelangen müssen"2) . . . "Noch frontal vom vorderen Pol des Corpus geniculatum externum ist diese Faserung deutlich zu sehen, so dass es den Anschein gewinnt, als mache die ganze Sehstrahlung einen leichten Bogen nach vorne und zum Teil naeb oben, bevor sie ihr Ziel erreicht"... "Weiter vorne in dem Pol des Temporallappens ist jedoch eine Degeneration nicht nachweisbar."3) Der horizontale Schenkel des Stratum sagittale externum bestehe aus kortikopetalen Sehfasern und Assoziationsfasern verschiedenster Provenienz, die teils die verschiedenen Okzipitalwindungen der medialen und lateralen Seite untereinander verknüpften, teils von den hinteren Okzipitalregionen nach vorne verliefen. Diese reichliche Ausstattung mit Assoziationselementen bestätigt auch den Befund von Schaffer, der in einem Fall von amaurotischer Idiotie mit fehlender Sehstrahlung diese Partie erhalten fand“ . . „Jedenfalls sei der Anteil an Fasern aus dem G. hippocampi, wie unser Fall H. zeigt, ein beträchtlicher." Nichtsdestoweniger sehen wir, wie Fig. 58 S. 175 demonstriert, die basalen Bündel des Stratum sagittale externum, welchen irrtümlich eine Beziehung zur Hippokampuswindung zugesprochen wird, ,im leichten Bogen in die Spitze und laterale Seite des C. gen. ext. hinein ziehen (s. S. 175)." Also auch bei v. Stauffenberg

1) Wilhelm Freiberr v. Stauffenberg, Ueber Seelenblindheit. Wiesbaden, bei Bergmann 1913.

2) Ebenda. S. 196.

3) Ebenda. S. 192. 
kein Auseinanderhalten des ventral medialen von dem ventral lateralen Sagittallager. Wie wichtig dieses ist, wird weiter unten ausführlicher dargelegt.

Eine dritte Doktorarbeit aus der Genfer psychiatrischen Kliuik ${ }^{1}$ ), welche wieder die Folgen eines Okzipitallappenherdes an den langen Leitungsbahnen, die Degenerationserscheinungen zum Zwecke der Feststellung des Ursprungs, der Verlaufsrichtung und des Endes des F. l.i. verwertet. Der dargelegte Fall betrifft unser Thema, in dem das untere Längsbündel an der Stelle, an welcher es aus der Hinterhauptsrinde hervortritt, in seinem unteren und inneren Anteil von dem primären Herd ergriffen wurde. Der G. lingualis ist mit Ausnahme seiner obersten Partie zerstört gefunden worden. Im Anschluss an diesen Erweichungsherd liess sich eine konsekutive Entmarkung der Fasern des horizontalen Schenkels des F.l.i. deutlich nachweisen. Ferner zeigte sich dieselbe noch an weit vorne liegenden Schnitten, wo die Radiatio thalamica nichts von Entartung an ihren Fasern erkennen liess. Als man sich dem äusseren Kniehöcker näherte, stieg die entmarkte Zone gleichsam empor, sie nabm das untere Drittel des aufsteigenden Astes ein, das nächst höhere Drittel war von gesunden Fasern durchsetzt, und das obere Drittel wieder licht und faserleer. Das Areal der zugrunde gegangenen Fasern liess sich bis in den äusseren Kniehöcker verfolgen. Die Zellen desselben in seiner oberen medialen Hälfte, sowie diejenigen der entsprechenden Basis waren gut erhalten. Die übrigen, die untere laterale Gruppe glich einem Haufen feinen Sandes. Fine Schichtung konnte man nicht unterscheiden. Im Kniehöcker unterscheidet Dreyer zwei Markfasersysteme, bestehend aus Fasern, welche von aussen nach innen und von unten nach oben ziehen, und aus solchen entgegengesetzter Richtung. Die ersteren Fasern seien dick und liessen sich bis in den F. l. i. verfolgen, letztere seien zarter und leiteten ihren Ursprung aus der Thalamusgegend her. Jene fehlten im linken C. g. ext. Diese treten daher um so deutlicher hervor. Am ausgesprochensten sei dieses Verhalten im hinteren und unteren Abschnitt des C. g. e. Im Innern desselben nehmen beide Fasersysteme beinahe die gleiche Richtung von oben nach unten und lassen sich daher weniger gut voneinander unterscheiden. Mit Recht betont Dreyer, dass die Marklamellen des C. g. e. nicht den Bündeln im Vicq' d' Azyr'schen Streifen der Hirnrinde vergleichbar sind, denn diese sind von den sekundären Degenerationen der Projektionsfaserung unabbängig, jene im Gegenteil ausserordentlich reduziert.

1) Serge Dreyer, Etude d'un Foyer occipital. Genève 1914. Thèse595. 
In jüngster Zeit hat Brouwer ${ }^{1}$ ) im Niederländischen Zentralinstitut für Hirnforschung in Amsterdam an zwei Fällen von alten Erweichungen des Hinterhauptlappens Gelegenheit gebabt, auch über die Frage, ob der F.l.i. ein Projektionssystem oder eine lange Assoziationsbahn sei, schlüssig zu werden. Brouwer meint, dass der Fasciculus longitudinalis inferior nicht allein ein Projektionssystem sein könne, ginge aus der Analyse seiner Fälle hervor. "Diese sind deshalb geeignet für die Beurteilung der Frage, ob in diesem Stratum sagitale externum nur Projektionsfasern verlaufen, weil die primären Herde so weit okzipitalwärts liegen"... "In dem beschriebenen Teil dieser Arbeit ist erwähnt worden, dass in meinem ersten Fall" (es handelte sich um eine Erweichung in beiden Hinterhauptslappen) die Intensität der Degeneration in der Richtung vom Okzipitalhirn nach dem Zwischenhirn allmählich geringer wird. Das trifft zumal für das Stratum sagittale internum zu, ist jedoch auch im Stratum sagittale externum - also im Fasciculus longitudinalis inferior - nicht zu verkennen. Auch in dem zweiten Fall, wo der Herd in der Kalkarinazone liegt, ist dieses ebenfalls deutlich zu sehen. Es müssen sich also dem Fasciculus longitudinalis inferior allmählich Fasern beigesellt haben. Man sieht auch deutlich auf den Weigert-Palpräparaten, dass sich dem weissen Bande des degenerierten Stratum sagittale externum zahlreiche Fasern aus dem tiefen Mark des Gyrus angularis und den Temporalwindungen hinzufügen, welche zum Teil dieses Stratum sagittale externum nur durchqueren, um das Tapetum und das Stratum sayittale internum erreichen zu können, zum Teil jedoch darin bleiben und im Fasciculus longitudinalis inferior selbst weitergehen. Diese Assoziationsfasern bilden sogar nach meiner Meinung weithin die Mehrzahl der Fasern in dirsem Bündel. Das geht deutlich aus dem Studium der rechten Hemisphäre meines ersten Falles hervor. Hier war im Okzipitallappen der ventrale Abschnitt der Sehstrahlung vollkommen zerstört worden, so dass die optischen Fasern degeneriert waren. Brim Frontalwärtsgehen in der Schnittserie erscheinen nun aus den Läppchen des Gyrus lingualis, fusiformis und hippocaropi neue Fasern, welche sich zu Strata sagittalia bilden (Zeichnung 6 und 7). Diese sind wohl schmäler als normaler Weise, aber nicht viel, obscbon sie absolut keine optischen Projektionsfasern besitzen".

Ich habe die Gedankengänge auch dieses Autors wortgetreu wiedergegeben, um zu exemplifizieren, auf wie schwankenden Füssen die apodiktisch auftretende Beweisführung, dass der F. l. i. ein Assoziations-

1) Brouwer, Ueber die Sehstrahlung des Menschen. Monatssohr. f. Psych. u. Neurol. Bd. 41. 
system sei, zu stehen pfiegt. Während andere Autoren wie Charogorodsky und Ferrière die Verkleinerung der Degenerationszone des F.l.i. nach vorne zu aus einer Abgabe von Fasern aus dem F.l.i. an die Rinde der umgebenden Windungen erklären, sieht Brouwer keine andere Möglichkeit als den Hinzutritt gesunder Fasern. Wer aber gewohnt ist, Frontalschnitte von Weigertpräparaten zur Kontrolle mit Sagittal- und Horizontalschnitten zu vergleichen, weiss, dass sehr oft ein Rest quergetroffener Markbündel sich zu vergrössern und dadurch das lichte Degenerationsfeld einzuengen scheint, wenn die einzelnen erst quergetroffenen Fasergruppen ein wenig auseinander treten, oder schräg getroffen werden. Ist aber kein Rest des F. I. i. mehr vorhanden, so pflegen, und das ist ganz gesetzmässig, die normale Markfaserung der Umgebung das entmarkte, faserlose und widerstandsunfähige Gewebe räumlich einzuschränken, indem es teilweise an seine Stelle tritt. Die Verkleinerung der faserleeren Babn des F.l.i. erklärt sich also ganz anders.

Das ist aber nicht der einzige Grund. Brouwer legt dem Umstand grosse Bedeutung bei, dass in das weisse Band des F.l. i zahlreiche Fasern aus dem tiefen Mark des $G$. angularis und der Temporalwindungen einstrablen und zwar nicht nur um dasselbe zu traversieren, sondern um in ihm zu bleiben und nach vorne weiter zu ziehen. Wie lässt sich aber entscheiden, ob einstrahlende Fasern im Stratum des F. l. i. verbleiben und weiterziehen, wenn dasselbe durch sekundäre Entartung ganz faserleer und schmäler geworden ist. Herr Brouwer glaubt dies offenbar daraus schliessen zu dürfen, dass er solche bis in den F. l. i. und nicht weiter verfolgen konnte, damit meinte er, sei die Sache bewiesen. Ein intensiveres Studium von Schnittpräparaten lehrt jedoch, dass die scheinbar einbiegenden Fasern in Wirklichkeit abgeschnitten sind. Sehr deutlich lässt sich diese Täuschung an den steifen, parallel gestellten Balkenfasern, welche alle, die Strata sagittalia querend, in die Tapetumschicht eindringen, demonstrieren. Dagegen ist die Beobachtung richtig, dass aus dem G. lingualis, nur wenn man die latero-ventrale Fasergruppe von der medio ventralen nicht trennt, auch aus dem G. hippocampi ein Faserkontigent des Stratum sagittale externum entspringt. Wie wir aber unten sehen werden, gehen die Projektionsfasern für den Spornteil des äusseren Kniehöckers aus dem vorderen Abschnitt der Zungenwindung hervor, was durch Brouwer's Fall nur bestätigt wird. Die Faserung, welche im G. hippocampi endigt, steigt im Schläfelappen herab, ohne mit dem Okzipitallappen irgendwelche Beziehungen zu haben. Natürlich musste daher Brouwer das vollkommen degenerierte ventrale Feld des F. 1.i. des Hinterhauptlappens mit normalen Bündeln besetzt finden, da die angefübrten Windungen von primären Läsionen 
Ursprung und Verlauf der basalen Züge des unteren Längsbündels. 305

verschont geblieben waren. Wir sind daher keineswegr genötigt, der Behauptung des Autors, dass diese normale Faserung überhaupt keine Projektionsfasern besitze, beizustimmen.

Ich habe im Vorstebenden Methoden und Deduktionen jener Erforscher des unteren Längsbündels, deren Abhandlungen mir zugänglich gewesen sind, möglichst getreu, und vielfach an den Wortlaut der Verfasser mich klammernd wiedergegeben, um zu zeigen, wie es möglich war, dass ein so einfacher und, wie wir sehen werden, nur durch wenige Schnittpräparate leicht zu klärender Tatbestand, durch die Anwendung unzureichender llittel und verkenrte Wege lange Zeit hindurch nicht erkannt wurde.

Rekapitulieren wir noch einmal zusammenfassend, welche Arten der Methodik die Suchenden auf falsche Fährte leiteten, so sehen wir:

1. Bei Burdach und Meynert die Abfaserungsmethode in Uebung, welche durch willkürlichste Zusammenfassung naheliegender, aber sich kreazender ganz heterogener Fasersysteme, insbesondere wegen ihrer Unfähigkeit spitzwinklige Biegungen zur Darstellung zu bringen, zu den folgenschwersten Irrtïmern geführt hat, deren Bann auf der Lehre von den Leitungsbahmen noch heute lastet.

2. Als die anatomische Schule Wernicke's die Schnittserienmethode mit der Weigert-Palfärbung in Anwendung brachte, glaubte man, am transparenten gefärbten Durchschnit den kunstvoll in einander gefügten Leitungsmechanismus des Grosshirns in seinen einzelnen Bestandteilen durchschauen zu können. Man übersah, dass die im Schnittbilde sich gegenseitig vielfach deckenden und krenzenden Faserstïmpfe einer subjektiven Deutung weiten Spielraum liessen, und dass es unschwer gelingen mochte, die von der Abfaserungsmethode mehr geahnten, als erschlossenen, traditionellen Zusammenhänge im Schnittbild wieder za entdecken. Das der Grund, warum sich die Fabel vom Fasciculus longitudinalis inferior, vom Fasciculus uncinatus, vom Fasciculus arcuatus, kurzum von den Iangen Assoziationssystemen, bis auf unsere Tage fortgeerbt hat.

3. Später erkannte man den enormen Vorteil, welchen das Studium sekundärer Degenerationen, entweder durch Verfolgung der erkrankten entmarkten, oder durch das Freiwerden der noch normalen Systeme, durch das Verschwinden der sie verdeckenden Umgebung hatte. Man bevorzugte wohl aus technischen Rücksichten allenthalben den Vertikotransversalschnitt und wollte Verbindungen bei örtlicher Vergrösserung oder Verkleinerung des Querschnittareals eines Faserzugs durch Supposition von $\mathrm{Zu}$ - und Abgängen von Fasern konstruieren. Die Existenz solcher Verbindungen kann aber nur durch übereinstimmende 
Befunde an Schnittpräparaten verschiedener Richtung mit ergänzender Heranziehung entwicklungsgeschichtlicher Präparate exakt bestimmt werden. Die Bahnen besitzen nicht selten örtliche Eigentümlichkeiten des Verlaufs, die sich nur auf gewissen Schnittebenen klar überblicken lassen. Das Studium von Frontalschnitten reicht daher allein zu zuverlässigen Schlussfolgerungen nicht hin.

4. Für die ventralen $Z$ üge des F. l. i. ist es verbängnisvoll geworden, dass man die laterale Gruppe, welche am Boden des Hinter- und Unterhorns, an der Markwurzel des G. fusiformis und der dritten Schläfewindung mit der Bündelformation im Zentrum des G. hippocampi wegen ihrer unmittelbaren Nachbarschaft, sowie ihrer morphologischen Gleichartigkeit als eine Einheit ansprach und weil man Fasern aus der Letzteren im G. hippocampi und Unkus endigen sah, auch auf eine Einstrablung des Ersteren in Rindengebiete dieser Windungen zurückschloss. Da man die basalen lateralen Züge des F.l.i. mit Recht aus Windungen des Hinterhauptlappens entspringen liess, mussten dieselben ganz folgerichtig eine assoziative Verknüpfung $z$ wischen Hinterhauptslappen und Schläfelappen berstellen. Nachdem aber, wie unsere schrägsagittalen Schnitte (siehe Abschnitt 2 die Figg. 7, 8, 9, 10) schön demonstrieren, der Fasciculus G. hippocampi nicht aus dem Hinterhauptslappen kommt, sondern im G. limbicus herabsteigt und sich erst beim Erscheinen der Hippokampuswindung dem F.l.i. medialwärts an die Seite stellt, so schwindet jeder Anhalt für die Annahme, die ventralen Bündel des F. l. i. seien ein Assoziationssystem zwischen Hinterhaupts- und Schläfelappen.

II.

Wenden wir uns der Schilderung einer Reihe von Durchschnitten $\mathrm{zu}$, welche in schräg sagittaler Richtung so ausgeführt wurden, dass man vom äusseren vorderen Schläfelappen zum hinteren inneren Okzipitallappen gelangte.

Das Schnittbild der Fig. 1, T'af. I, bringt die vordere Hemisphärenhälfte. Es liegen Schläfe- und Stirnlappen sowie die Pars opercularis Rolandica vor. Von unversehrten Windungen des Klappdeckels sticht der arg mitgenommene Schläfelappen grell ab. Im ganzen äusserst geschrumpft, die Rinde strukturlos, am Pol zerrissen, löcherig, morsch, brüchig, in formlose Fragmente zerfallend; der Hemisphärenkern fast vollständig faserleer, nur einzelne, schmale, der Rinde unmittelbar anliegende Reste der kurzen Assoziationssysteme sind erhalten. Aus dem deformierten Windungskomplex werden die Bildungen der drei Tempotalwindungen kenntlich, deren Formationen um so schärfer hervortreten, je weiter wir okzipitalwärts gelangen. Der Kopf der temporalen Querwindung weist in seiner hinteren Hälfte nur ein wenig verändertes Aussehen 
auf. Der Radiärfaserung parallel sieht man in der vorderen Hälfte dieser Windung weisse Streifen, Mark und Rinde durchsetzend. Die vordere Rindenhälfte derselben sowie der Kortex des kollabierten vordersten Anteils sind von mehreren lücken durchbrochen. In auffallendem Gegensatz zu seiner pathologisch schwer verwandelten Umgebung läuft tiefdunkel, von normaler Konfiguration und Stärke, der basale Schenkel des unteren Längsbündels von hinten nach vorne, bis er spitzwinkelig umbiegt, um dann plötzlich aus der Schnittebene zu treten. Der Anschein, als würde das Bündel nach vorno zu breiter, wird durch die Lage einer grösseren Fasergruppe bedingt, welche in die Schnittebene fällt. Tinktion, Kaliber und Anordnung der Elemente lassen keinen $Z$ weifel an der Natur dieser in die Augen springenden Formation aufkommen. Es kann sich nur um das Stratum sagittale externum handeln. Die innere Sagittalfaserschicht, unter normalen Verhältnissen das breitere, reichere Faserareal ist hier zu einem dürftigen Saum zusammengeschrumpft. In Farbo und sonstiger Beschaffenheit gleicht sie dem zentralen Mark der einzelnen Windungszipfel. Ebenso faserarm und atrophisch ist die innerste Lage, diejenige des Tapetums. Dass oin Faserabgang vom kompakten Strang des F. l. i. in die umliegenden Windungen nicht stattfindet, tritt ganzeinwandfrei hervor. Ebensoklar und deutlich ist diebrüske Umkehr des ganzen Faserzugs unweit der Scbläfelappenspitze ohne jede Einstrahlung in dieselbe. Das vollkommon intakte Aussehen des F. 1. i. auf gänzlich entmarktem Grunde ist ein typisches patbologisches Zustandsbild (siehe etwa v. Stauffenberg's, Ueber Seelenblindbeit, S. 176, Fig. 58). Der selbst gesunde Faserzug durchstreift eine Gegend, in welcher 2war kein primärer Herd liegt, deren Markgebilde jedoch durch die Wirkung benachbarter Zerstörung in weitem Umfang krankhaft verändert sind. Der F. 1. i. ist eben-das oinzige lange Fasersystem, welches den vorderen Schläfelappen nur durchzieht und darum heil davonkommt. Diese Unabhängigkeit vom vorderen Schläfelappen kann nicht anschaulicher dargestellt werden. Ebonso prägnant springt die 'Tatsache ins Auge, dass der F. 1. i. in die temporale Querwindung, welche gerade über demselben teils primär affiziert, teils sekundär entartet in dieser Ebene sichtbar ist, keine Zuzüge an Fasern entsendet. Dio Bündelpakete des F. l. i. hören nach oben zu mit einer jähen linie auf, da sie hier aus der Schnittebene verschwinden.

Fig. 2, Taf. 1. Der Sagittalabschnitt liegt der Mittellinie ein wenig näher. Eine Lücke im Zentrum des bier sehr ausgedebnten lichten Feldes zeigt das Hereinragen des primären Herdes an. Von diesem setzt sich ein kompaktes weisses, sich allmäblich nach vorne zu verschmälerndes, in den Markkörper der temporalen Querwindung scheinbar einlaufendes Band, welches um so schärfer herausgezeiohnet ist, als einzelne stehen gebliebene Fasern dasselbe oben und ein ganz schmaler Saum von solchen unten einfassen, fort. Okzipitalwärts vom hinteren Rande der Erweichungslücke sieht man das Negativ der eben geschilderten Degenerationsverhältnisse, ein Büschel gefärbter Fasern, von weissen Streifen eingerahmt, welches strangförmig zusammengefasst in die Hinterhauptswindungen hinabsteigt. Um die Lage des im Zentrum des Hemi- 
sphärenmarkes bezeichneten Defektes, welche die Bündelmassen der dorsalen Sehstrablungen entzwei schnitt, richtig zu beurteilen, überblicken wir die Folge der Windungen, wie sie sich rom Stirnende okzipitalwärts entwickeln. Betrachten wir die über der Sylvi'schen Spalte in die Schnittebeno fallende Gyrireihe, so treten, durch kräftig tiefe Rindenstruktur hervorgehoben, zwei Windungen $\mathrm{Ca}$ und $\mathrm{Cp}$ entgegen, welche die vordere und hintere Wand eines tiefen, queren Einschnittes c, dessen Grund sich nach vorne schiebt, bilden. Wir erkennen in ihnen unschwer die vordere $\mathrm{Ca}$ und hintere Zentralwindung Cp. Die Rinde der vorderen Zentralwindung verliert etwa auf dem Gipfel eines breiten Windungsrückens ziemlich plötzlich ihr charakteristisches Aussehen, wodurch sich der Uebergang in den Kortex des Stirnhirns deutlich markiert. Der absteigende Ast des Sulcus praecentralis ragt noch nicht in die vorne rechts lateral geführte Scbnittebene hinein, weshalb die Pars opercularis frontalis mit dem Operculum Rolandicum zu konfluieren scheint. Die nächste vertikale Furche ist der aufsteigende Ast der Fissura Sylvii, welcher die Pars opercularis von der Pars triangularis des Stirnhirns trennt. Das Markzentrum des operkularen Anteils der Zentralwindungen ist zweifellos pathologisch gelichtet, was auf einen Ausfall längerer Fasern im Bogenbündel der Sylvi'sehen Spalte zurückführbar ist. Vergleicht man diesen Degenerationsbefund mit der Intaktheit des Markinnern des Operkulums an dem oben betrachteten Präparate (siehe Fig. 1, Taf. 1) und demjenigen der Pars triangularis, so erhellt hieraus, dass der Fasciculus arcuatus, mit welchem, wie bereits erwähnt, das Bogenbündel der Sylvi'schen Spalte identisch ist, aus langen und kurzen Fasern sich zusammensetzt. Der Schläfelappen zeigt sich auch in diesem Präparate vollkommen geschrumpft und entmarkt, vornebmlich ist os die erste Schläfewindung, welche zusammengedrückt ist. Ein primärer Herd, welcher die Spitze zerfressen bat, gibt hierfür eine Erklärung. Die von primärer Läsion freie temporale Querwindung entbehrt hier anscheinend aller langer Fasersysteme. Ein Einstrahlen der entmarkten Sebstrablung, zu welchem erstem Eindruck die makroskopische Betrachtung verleiten könnte, existiert, wie sich bei Lupenvergrösserung zu erkennen gibt, nicht. Das Loch im Zentrum des Präparates entspricht seiner Lage nach der Malazie im unteren Scheitellappen.

Von den in der Ebene sich darbietenden Gebilden fosselt der auch bier vollkommen intakte Schenkel des unteren Längsbündels am meisten unsere Aufmerksamkeit. Die okzipito-temporale Halbstrecke ist etwas sohmäler als auf dem in der Fig. 1, Taf. I, wiedergegebenon Präparate. Ihr okzipitales Ende in den beiden hintersten, untersten, mit dem scharfen Vicq'd'Azyr'schen Streifen ausgezeichneten Windungszipfeln des Hinterbauptslappens ist mit der Lupe leicht und einwandfrei feststellbar. Dieselben gehören zweifellos der Unterlippe der Fissura calcarina, somit dem G. lingualis an. Erwägt man, dass bereits der Durchschnitt des dritten Windungszipfels - von hinten nach vorne gerechnet - die charakteristische Streifung nicht mehr trägt, und dass die Ebene des ganzen Hemisphärenschnittes, worauf mehrfach hingedeutet wurde, von binten innen nach aussen vorne läuft, demnach mit der Sagittalen einen nacb voıne offenen, spitzen Winkel bildet, so müssen wir die vorder- 
sten medialen Gyri der Area striata vor uns haben. Der Strom der basalsten Bündel des F. l. i. ergiesst sich also in kompakten Zügen in den vorderen Absohnitt der Zungonwindung. Der vordere kürzere Anteil derselben ist etwas scbräg getroffen, so dass die in der Ebene zur Anschaung gelangenden Faserstümpfe durch Bereicherung solcher aus mehr nach innen situierten Bündeln an Zahl gewonnen zu haben scheinen. Die Umkebr im vorderen Schläfelappen geschieht hier in weniger spitzem Winkel als am erstgeschilderten Präparate. Der absteigende Schenkel tritt auch hier, linienscharf abbrechend, plötzlich aus der Schnittebene.

Das Stratum sagittale internum basale, welches den F. 1. i. medialwärts begleitet, sonst an Faserzahl und Gesamtbreite denselben übertrifft, ist hier in ein ganz schmales, kaum sichtbares, lichtes Band verwandelt, dessen Existenz nur am Knie kenntlicher hervortritt. Daraus darf auf eine Faserarmut an mehreren Stellen, sogar Faserbarheit geschlossen werden. Die Entartung dieser Bündel, welche deren Untergang begründet, ist durch die ansehnliche Erweichung im unteren Scheitellappen offensichtlich hervorgerufen, welche di $\theta$ aus den Ganglien der Hinterhaupts- und Scheitellappen entspringenden Fasern von ihren trophischen Zentren getrennt hat. Auch der Balken, das Tapetum ist in der Scheitelgegend vollkommen durchbrochen und zerstört worden, so dass die weissen Kegel in den Markkernen der Gyri der dritten Schläfewindung, soweit dieselbe vorne nicht gänzlich faserleer ist, sich aus der Entartung der beiden Fasersysteme verstehen. Ein isolierter lapotumrest aus longitudinal getroffenen Elementen schwebt parallel zu der Pars descendens, ohne dass seine Endigungen in der Rinde sich nachweisen liessen.

Fig. 3, Taf. I. Der frontale Abschnitt einer sich wieder mehr der Mittellinie rähernden Ebene, deren Einzelheiten beim Ueberblick kaum eine merkliche Aenderung gegen die Formationen des zuvor geschilderten Präparates verraten.

In der oberen Hälfte ragen die beiden Zentralwindungen $\mathrm{Ca}$ und $\mathrm{Cp}$ durch ibren kortikalen Markfaserreichtum hervor. Die vordere, durch ein dichtes, radiäres Markfasernetz und eine auffallende Breite der Kinde sofort erkennbar, die hintere durch ihre charakteristische Schmalheit und die zierliche, schärfer konturierte, horizontale Faserschicht ihre morphologische Eigentümlichkeit anzeigend. Sowohl das Köpfchen der vorderen Zentralwindung als die hintere Wand der Zentralfurche ist von kleinsten Erweichungsherdchen durchsetzt. Der Körper der vorderen Zentralwindung, welcher in der vorhergehenden Figur sattelförmig gedellt erschien, zeigt sich hier durch eine Furche eingeschnitten. Eine bestimmte Grenze zwischen der Rinde der vorderen Zentralwindung (Ca) und des Stirnbirns lässt sich nach der Aenderung der Rindenstruktur nicht angeben, da die Rindenzipfel der vorderen Hälfte der $\mathrm{Ca}$ in anderer Richtung durch den Schnitt getroffen sind. Sicher ist die mit $\mathrm{v}$ bezeichnete Furche, der aufsteigende Stirnast der Sylvischen Spalte. Das ganze tiele Mark des Klappdeckels, bis in den Stirnanteil binein, ist durch unzweifelhafte, sekundäre Degenerationen aufgehellt, woraus hervorgeht, dass die Markschoiden langer Fasern, die aus den primär zer- 
störten Gebieten der Scheitel- oder Schläfengegend stammen müssen, zugrunde sind. Diese Tatsache erlaubt den weiteren Sohluss, dass solche, zwischen ontfornteren Rindenstellen existierende Verbindungen existieren müssen.

Die obere Rindenfläche der ersten Schläfenwindung am Pole und dessen Umgebung ist malazisch, desgleichen die vordersten $\mathrm{T}_{2}$ und $\mathrm{T}_{3}$. Von den mit Hämatoxylin, wenn auch nur mehr schwach tingierbaren Bündeln sehen wireinen Assoziationsfaserzug aus der tiefen temporalen Querwindung in die Rinde des Temporalpoles strablen.

Das Knie des basalen unteren Längsbündels, dessen oberer verbroiterter Schenkel leicht bogenförmig geschwungen an den verschmälerten horizontalen Abschnitt in spitzem Winkel sich ansetzt, imponiert, sioh von seiner erkrankten Umgebung scharf abhebend, auch hier durch den unverminderten Reichtum kräftig gefärbter Bündel, die mit einem Male aus der Schnittebene treten und daher stumpfförmig abgeschnitten erscheinen. Wir sehen weder in den noch steben gebliebenen Rindeninseln Markfasern aus dem F. 1 . i. einstrahlen, noch aus denselben entspringen und sich dem Knie näbern oder demselben gar zugesellen. Eine irgend erbeblichere Anzabl von Fasern, die bestimmt wären, im F.l.i. die Rinde des vorderen Schläfolappens mit dem Hinterbauptslappen za verknüpfen, ist daher mit Bestimmtheit aususchliessen.

Anders verbält sioh das Stratum sagittale internum, welches medialwärts vom F. l. i. gelagert, dessen Bogen mitmacht. An normalen Präparaten übertrifft die innere Sagittalschicht an Umfang beträchtlich die äussere, hier ist dieselbe kaum balb so stark. Die dritte, ganz innerste Lage, welche ebenfalls faserleer und reduziert ist, setzt sich im gesunden Gehirn aus Tapetumfasern zusammen, muss also von dem ihr an Farbe sehr nahestehenden und scheinbar oine Einheit bildenden Stratum sag. ext. getrennt werden. Dio Ueberoinstimmung des Farbentons des letzteren mit demjenigen des vorderen Schlärelappens sowie die Einbusse an Umfang des Areals legt einen Zusammenhang und Fasernaustausch zwischen den beiden Markgebieten nahe. Der Irrtum oben zitierter Autoren, welche Ausstrahlungen aus den basalen Sagittalschichten in den vorderen Schläfelappen beobachtet baben wollen, dürfte sich daher, soweit sich dies auf die äusseren Partien des vorderen Schläfelappens bezieht, dahin aufklären, dass niobt das Stratum externum, sondern internum, allerdings nicht als Verbindungsstrang zwischen $z$ wei Rindenstellen Markfasern aus den bier lädierten Rindenbezirken aufnimmt.

Fig.4, Taf. II. Die frontale Hälfte eines medialer gelegenen Durchschnittes: Die beiden Zentralwindungen sind hier durch die Eigenart der Rindenstruktur keineswegs so markant als in der zuvor betrachteten Schnittebene. Es beweist dies, wie entscheidend für das strukturelle Rindenbild die Schnittrichtung ist. Während dieselbe in der Ebene der Fig. 3, Taf. I, ziemlich senkrecht zu ibrem Verlauf getroffen ist, scheinen die Zentralwindungen, vornehmlich die vordere schräg und ungleich dick geschnitten za sein. Der Sulcus praecentralis ist hier bereits bis zum tiefsten Grunde entwickelt. Die langen Fasern des Bogenbündels der Sylvisohen Spalte sind bis in das tiefe Mark der Pars triangularis frontalis 
Ursprung und Verlauf der basalen Züge des unteren Längsbündels. 311

sekundär entartet. Die Durchschnitte der mittleren und hinteren Inselwindungen tauchen auf. Der Herd an der oberen Rindenfläche der ersten Schläfewindung ist bedeutend kleiner geworden. Dagegen ist die zweite Schläfewindung bis tief ins Mark hinein von pathologischen Lücken durchsetzt und kollabiert. Der ganze vordere Schläfelappen ist bis auf das bereits in der Fig.4, Taf. II, sich deutlich abhebende, einzig noch stehen gebliebene, die temporale Querwindung mit der Schläfelappenspitze verbindende Assoziationssystem, marklos.

Der Stabkranz des hinteren Grosshirns, welcher am Normalpräparat einen kontinuierlichen strablenförmigen Halbkreis von der hintersten Operkulargegend bis zu den basalen Bündeln des F.l.i. darstellt, ist hier, etwa in seiner Mitte, in der Höhe der temporalen Querwindung, durch einen weissen Streifen unterbrocben, welcher sich unschwer als die vordere Fortsetzung des von dem parietalen Herd zur Entartung gebrachten und bei der Beschreibung der Fig. 2, Taf. I schon geschilderten Bündelklomplexes erkennen lässt. Aus der Gestalt seiner Begrenzung lässt sich der Verlauf der ausgefallenen Fasern rekonstruieren.

Die Pars horizontalis des F.l.i. ist hier aus der Schnittebene bereits ausgetreten. Die Rundung seiner Umkehr ist zu einem vollständigen weichen Knio gedieben. Von ganz entmarktem Grunde hebt sich die hier herabziehende und umbiegende ganz normal gefärbte Bündelmasse ab. Die malazischen Lücken im vorderen Schläfelappen treten hart an den vorderen Rand der intakten Faserkurvaturheran. Die dunkeln Markmassen werden durch lichte, aus dem faserlosen Grundplan durcbziohende Spalten in Pakete gegliedert. Dies gilt für den ganzen vorliegenden Teil des basalen Längsbündels, sowobl für die Pars descendens als für das Knie selbst.

Die Unversehrtheit des F.I.i. auf dem vorliegenden Schnittbilde, trotz der tiefgreifenden Zerstörung des vorderen Schläfelappens, ist der unwiderleglichste Beweis dafür, dass der basale Anteil weder in der Spitze des Schläfolappens entspringt noch in derselben endigt, sondern vom Thalamus herabsteigend, mit recht steiler Biegung okzipitalwärts zieht.

Fig. 5, Taf. Il. Ein Hemisphärensegment, welches den Verlauf des absteigenden Schenkels des F.l.i. zur Ansohaunng bringen soll. In die Schnittebene fallen ein unteres Fragment des Linsenkernes mit den in schräger Breite getroffenen Markstrablungen der inneren Kapsel, die Impressiones digitatae des Ammonshornes, die einen Aufsatz der Hippokampuswindung bilden, endlich zu unterst der vordere äussere Schläfelappen mit einer Erweichungslücke, unweit der temporalen Spitze. Der Schläfelappen rubt auf einer Kleinhirnhemisphäre.

Der absteigende Schenkel des F.l.i. zieht, wie ersichtlich, in leicht geschwungenem Verlaufe, unter der Linsenkernbasis hinwegkriechend, berab. Man gewahrt, dass er dem Knie, wolches in dieser Ebone nur mehr aus weit spärlicheren Elementen zasammengesetzt ist, schräg nach innen geriohtet, sich anfügt. An einer kleinen Stelle reicht die Erweichungslücke mit einer Spitze in das Knie und scheint es zu durchbrechen. 
Fig. 6, Taf. II, stellt das Linienschema eines in der Frontalansicht sich darbietenden äusseren Kniohöckers dar, welches ich zur Erleichterung des Verständnisses der folgenden Schnittpräparate deren Schilderung voranstelle. Wir sehen die charakteristische Glookenform an der Basis gedelit, an deren Gan. glienketten die Fasern des Tractus opticus sich aufsplittern, weshalb wir diesen Teil des C.g.e. mit $\nabla$. Monak ow als Traktusteil T'. bezeichnen. Lateralwärts verjüngt sich das Kniehöckerganglion in einen sporngleichen Fortsatz, weshalb dieser Abschnitt den Namen des Spornteils 5 fïhrt. Aus den Ganglienkränzen der Kuppe mit ihrem lateralen Abhang, also auch der Dorsalfläche des Spornteils entspringt die zentrale Sebbahn. Dieselbe liegt in ibrem kompakten Austritt aus dem äusseren Kniehöcker hier vor und gliedert sich, durch verschiedene graphische Ausführung greifbar versinnlicht, in eine punktierte, zylindrische Zone, welche der Kniehöckerkuppe aufgesetzt ist, und eine dunkel gehaltene Fasermasse, welche aus der lateralen Fläche des C.g.e. und aus dem Rücken dee Spornteils garbenförmig emporstrebt. Die punktierte Hälfte der austretenden Sehstrahlung verbildlicht den Umfang des entarteten Anteils, während die schraffierte den noch intakt gebliebenen, basalen Schenkel bei seinem Ursprung kennzeichnot. Die rotpunktiorten Linien mit den Zahlen 7 , 8, 9, 10 sind in dem Sinne gegen die Mittellinio geneigt, in welchem die Schnittrichtung von hinten nach vorne geführt wurde, um die Kalkarinawindungen und die Gyri temporales profundi in gewissen Ebenen gleichzeitig zu Gesicht zu bekommen.

Fig. 7, Taf. II, lässt vor uns die vordere Hälfte eines Sagittalschnittes durch Grosshirn, Linsenkorn und Thalamus opticus erscheinen. Den basalen Abschluss des Bildes gestaltet das vordere Segment eines Sagittalschnittes durch eine Kleinhirnhemisphäre. Der mächtige Kopf der vorderen Zentralwindung (Ca) mit seinem tief dunkeln breiten Rindenkamm dient zweckmässig als Orientierungspunkt für das topographische Verständnis einer Reihe sich hier aufrollender Einzelheiten. Das Zentrum nehmen die grauen Massen des. Jinsenkernes und nach hinten des Sehhägels ein. Von ersterem ragt das, durch die ungewöhnliche Schnittrichtung fast kugelrunde Putamen hervor, an welches sich nach rückwärts und oben die hier äusserst dürftigen Glieder des Globus pallidus ansetzen. Das Putamen ist von zahlreichen dunkeln Punkten durchsetzt, welche nach dem Globus pallidus hin grösser und zahlreicher werden. Obne, an dem noob kleinen, in die Schnittebene ragenden Globus pallidus mebrere Glieder unterscheiden zu können, ist über demselben ein dichter verworrener Markfaserfilz gebreitet, der sich in sanftem Schwunge zu einem festen Strang sammelnd, nach hinten und innen hinauf steigt und die Capsula interna in ihren hintersten, innersten Paketen durchbrioht. Es unterliegt keinem Zweifel, dass die geschilderte Faserung mit der Linsenkernsoblinge identisch ist. Diese schliesst die Linsenkernbildungen nach hinten ab und trennt sio von dem schmalen, faserleeren Sehhügolpolster.

Das untere Drittel desselben wird von einer Formation eingenommen, welche in der Kniehöckerskizze der Fig. 7, Taf. II, die durch die rotpunktierte Linie 8 markierte Schnittebene enthält, nämlich der schräg getroffene Spornteil 
mit den austretenden Fasern der zentralen Sehbahn. Diese lassen sich mit freiem Auge, besser noch mit der Lupe an der Linsenkernbasis in den herabsteigenden Schenkel verfolgen. Ibre Kontinuität mit dem C.g. $\theta$. ist dem. nach bewiesen. Dem Durchschnitt des Kniehöckerspornes sitzt in Gestalt eines flachen Knöpfchens eine kleine dunkle, dichte Faserkapuze auf, welche sich nach dem Pulvinar scharf absetzt, also keine Ausstrahlungen in dieses schickt. Die in der Kappe enthaltenen Bündel schlagen sich über die Spornganglien, immer an diese geklammert. An den folgenden Präparaten der Schnittreihe wird die Zugehörigkeit und Abhängigkeit dieser Markbündel von der Spornwurzel offenbar.

Unten und vorne vom Spornknöpfehen, streckt sich diesem der von dem Marküberzug des bier in seiner T'otalität getroftenen Ammonshorns auslaufende Fornixstumpf entgegen. Während das Subiculum Cornu Ammonis intakt erscheint, ist der vorderste Scbläfelappen pathologisch zerfressen, Rinde- und Markunterschiede fehlen, überall Löcher und strukturloses Gewebe. Das Knie des F.l.i. ist schon aus der Schnittebeno getreten, einzelne Ueberreste der borizontalen Züge sind noch nachweisbar.

Aus der Linsenkernbasis, unmittelbar hinter einem hinabreichenden Zapfen tritt ein schwarzes, breites, schwertartig zugespitztes Band, dessen nnteres Ende sich den Elementen der Pars descendens scheinbar anlegt, die vordere Komnissur.

Nach aussen und vorne vom Linsenkern, in der Tiefe der Sylvischen Spalte, sehen wir zwei Inselwindungen hervortreten, durch die untere Querspalte vom Schläfelappen, durch die obere vom Stirnhirn geschieden. Die Capsula externa und extrema zeigen keine von Strangdegenerationen herrührenden Lichtungen, wenngleich im Inselmark eine Erweiterung der Gefäss $\theta$ (état criblé) aulfällig wird. Dor schwarze Rand der äusseren Kapsel des Linsenkernes, welcher dessen äussere Kante besonders scharf sich abheben lässt, setzt sich in die aus der Linsenkernbasis gleichsam herauswachsenden dicken Bündelstäbe der iuneren Kapsel fort, die nach der inneren Kante der letzteren plötzlich verschwinden, als ob sie ein Areal freiliessen, auf welchem die die Ansa lenticularis zusammensetzenden Faserbüschel deutlicher sichtbar würden. Dieses durch die Maschen der dunkeln Bündel blickende, an medialeren Ebenen weit eklatantere Degenerationsfeld der Capsula interna entspricht einem Ausfall an vorwiegend parietalen Fasergruppen.

Der hier vertikal einschneidende Sulcus praecentralis grenzt das Gebiet der Zentralwindungen vom Stirnhirn ab. Von diesem schliesst sich an die genannte Furche nach vorne hin die zweite Stirnwindung, von dieser durch eine tiefe, horizontal gestellte Furche abgeschnitten, senkt sicb die Pars orbitalis der dritten Stirnwindung, in reicher Entfaltung sekundärer Windungen bis über die Temporallappenspitze, als Dach der Sylvischen Spalte sich vorschiebend.

Es ist bemerkenswert, dass ein sekundär degenerierter Faserzug, welcher aus dem zerstörten vorderen Schläfelappen in die Frontallappenspitze oder deren Gegend liefe, also ein Fasciculus uncinatus, nicht nachweisbar ist. Im 
Stirnhirndach der Sylvischen Spalte, fast unmittelbar über der Rinde, welche den Inselwindungen gegenüberliegt, findet sich ein schmaler lichter Streifen, welcher einer Fortsetzung der grauen Säule des Klaustrums äbnlich sieht. Dieser bört aber schon an der nächsten Einknickung auf, an welcher sich die Rindenschale zu einer Furche einsenkt.

Fig. 8, Taf. III. Die in dieser Figur gebotene Schnittebene ist der zuvor eingebend Geschilderten in ihren anatomischen Vorkommnissen, weil der Mittellinie nur wenig näher liegend, so verwandt, dass ein Eingehen auf dieselben einer Wiederholung gleichkäme. Wesentlich erscheint das sukzessive Wachsen des Köpfchens des Kniehöckerspornes und das Abnehmen der aus Markfasern zusammengesetzten Kapuze. Dieser Veränderung wegen wurde das Schnittpräparat hier vorgeführt. Solch' gegensätzliches Verhältnis wird durch die Betrachtung der Kniehöckerskizze auf Fig. 6, Taf. II, klar. Schnitt 8 bringt alle noch erhaltenen Markfasern, die in das Kniohöokerganglion einstrahlen, da dieselben im Bogen ihren Ursprungsort aufsuchen. Das getroffene Stück des Kniehöckerspornes ist der äusserste Anschnitt. Fig. 9, T'af.III, rückt weiter nach innen, ein wenn auch nicht bedeutender Teil der Faserung ist in dem Spornteil versohwunden, während dieser selbst an Masse anschwillt.

Fig.9, Taf.III. C Zentralfurche, Ca vordere Zentralwindung, pr. Präzentralfurche, $\mathrm{F}_{2}$ zweite, $\mathrm{F}_{3}$ dritte Stirnwindung. Lichtungen in der zentralen Markwurzel der zweiten und dritten Stirnwindung, welche aber nicht eindeutig sind, da infolge Abgleitens des Messers - die von der Rindenbucht der Sylvischen Spalte zum Grunde der Zentralfurche ziebende Linie bezeugt dies das obere Drittel der Schnittfläche dünner geriet. Eher erweckten Verdacbt auf pathologische Entmarkungen die Lichtungen der Capsula extrema, da sich ein Zusammenbang mit dem schwer lädierten Schläfelappen geradezu aufdrängen würde. Hervorzuheben ist, dass das Mark der Pars orbitalis, trotz fast vollständiger Zerstörung der Temporallappenspitze nicht gelitten bat, dass es also lange Assoziationssysteme, welche die Spitze des Stirnlappens mit derjenigen des Schläfelappens in direkte Verbindung biingen, dass es einen Fascioulus uncinatus nicht gibt.

In das von der Fig. 7, Taf. II, reproduzierte Schnittbild tritt im Zentrum der unteren Markhälfte des G. hippocampi ein aus kräftigen Bündeln konstituierter Faserzug, welcher in seinem geradlinigen Laufe und imponierender Breite von der matteren, aus Assoziationssystemen gefügten Hintergrunde scharflinig sich abbebt. Die Trennung dieses Faserzuges rom F.1. i. an Horizontalbildern, auf welchen der Letztere die laterale, der Erstere die mediale Wand des Hinterhornes auskleidet, ergibt sich ron selbst. Hingegen ist eine irrtümliche Zusammenfassung beider zu einer anatomischen Einheit bei oberflächlicher Betrachtung von Frontalschnitten wohl möglich und hat den Hautgrund abgegeben, warum man geradedenventralen Abschnitt des F.l.i. als Assoziationssystem zwischen Hinterhauptslappenrinde und Schläfolappenrinde aufgefasst bat. Allein unser Faserzug F $H$ bat mit dor Hinterhauptsrinde gar nichts zu tun. Selbst bei vollständiger Er- 
weichung der medialen Okzipitalrinde wird dieses Bündel intakt gefunden (siehe Sachs, Das Gebirn des Förster'schen Rindenblinden. Wernicke's Arbeiten, 2. Bd., Taf. VII, Fig. 13). Ich habe dieses Bündel als Stabkranz des G. hippocampi bezeichnet und bemerke van Valkenburg gegenüber, welcher mir vorwirft, dass ich dies ohne entsprechende Begründung getan (sieho Psychiatrische on Neurologische Bladen, 1911, Nr. 4 en 5, S. 22, des Separatabdruckes), mich hätten dieselben morphologischen Merkmale hierzu bewogen, welche Redlich zu der gleichen Ansicht geführt: kräftiges Markfaserkaliber, Anordnung der Elemente, deren Langläufigkeit, frühzeitige Reife der Markscheiden (Hösel), Eigenschaften, welche wir an den zentralen Sinnesbahnen allein wahrnebmen. Flechsig erblickt daher in ihm einen Teil seiner Riechstrahlung. Auf Ursprung und Verlauf dieses offenbar wichtigen Faserzugs einzugehen, verbietet mir die Rücksicht auf das gestellte Thema. Soviel scheint mir jedoch sichergestellt, dass sich derselbe in der Rinde des G. hippocampi auflöst, vielleicht den sensiblen Schenkel jenes Reflexbogens bedeutet, dessen motorischer Strang der aus den grossen Zellen des Ammonshorns entspringende Fornix longus ist.

Das Kniehöckerknöpfchen hat sich hier in eine Bohne verwandelt, dessen obere Hälfte sich aus dicht stehenden hämatoxylitingierten Fasern zusammensetzt, während die untere schalenförmig den Markkamm trägt. Die Kontinuität derselben mit der Pars descendens des F.l.i. ist mit Lupenvergrösserung leicht erkennbar. Das Engenebeneinandergeben der Elemente an ihrem Ursprungsort, welche in dem Tiefdunkel des Markaufsatzes so sinnenfällig sich kundgibt, ist ein für alle Leitungsbahnen des Grosshirns geltendes Kriterium, worauf ich anderorts aufmerksam gemacht habe. Die von der Linsenkernschlinge, nach aussen und vorne, gelegene sekundär entartete faserleere Stabkranzzone ist hier breiter und kenntlicher.

Fig. 11, Taf. IV. Ca vordere, $\mathrm{Cp}_{\mathrm{p}}$ hintere Zentralwindung, c Zentralfurche, $\mathrm{F}_{1}$ erste, $\mathrm{F}_{2}$ zweite Stirwindung, $\mathrm{sf}_{1}$ Sulcus frontalis primus. Die Lichtung im Mark der ersten Stirnwindung ist nicht verwertbar, da sie von einer Linie anhebt, welche durch Abgleiten des Messers infolge verscbiedener Schnittdicke des Präparates entstanden ist. Dagegen können wir auch auf diesem Präparat die Helligkeit in Mark der dritten Stirnwindung mit mehr Recht auf pathologische Entmarkung beziehen, da sie sich an allen Durchschnitten der Serie fortlaufend wiederfindet. Ich führe sie auf den Schwund der Markscheiden jener Bündel zurück, welche aus der Schläfelappenrinde in den Operkularteil des Stirnhirns in vertikalem kürzestem Laufe ihren Weg nehmen. Dieser führt durch die äusserste Kapsel. Und doch vermissen wir in dieser ein kontinuierliches, weisses Band, das von den zerstörten Teilen des vorderen Schläfelappens zu der gelichteten Zone zu verfolgen wäre. Dies rührt einerseits daher, dass die kurzen Bogenbündel, deren Anfang und Ende in gesunden Rindengebieten liegen, mit ibren gefärbten Elementen die farblosen verdecken, andererseits davon, dass dieser Aufstieg der Bündel aus dem Schläfelappen in das Stirnhirn in frontalen Ebenen erfolgt. F S, die Sylvi'soho Spalte. Die an die innere Kapsel medialwärts und hinten stossende Zone ent- 
arteter Bündel, die durch die schneeweissen Riefen, welche ganz besonders an diesem Präparate durch das Dickicht des aus dem Linsenkern stammenden Faserfilzes hervorleuchten, sehr deutlioh erkennbar ist. An diese schmiegt sich, nach oben und innen sich werfend, die Linsenkernschlinge, und nach unten und hinten von dieser liegt im atrophisohen Pulvinar die zu ansehnlichem Um. fang entfaltete graue Bobne des äusseren Knieböckers (vgl. hierzu Fig. 7, Taf. II, die rotpunktierte Linie mit der Nummer 10). Mit nicht armiertem Auge bereits sieht man den oberen Rand des Knieböckers markfaserfrei. Die Markfaserkappe ist verschwunden. Wir sehen an ihrer Stelle einen unscharf begrenzten Fleck inmitten des Kniehöckerganglions über einem dorsal scharf begrenzten Kerne. Mit der Lupe lassen sich an der oberen Kante des Kniehöckers mehrere Konturen unterscheiden. Diese Bildungen sind dahin zu interpretieren, dass der Schrägschnitt am oberen Rande des C. g. e. schon durch die faserleere Zone gefübrt wurde, während er in der Mitte, in dem dorsal linienscharf abgesetzten Ganglienabschnitt desselben, noch die erhaltenen Strahlungen des Spornteils erreichte. Makroskopisch sieht man drei feine Markfäserchen in stark geschwungenem Verlauf, mebrere nach oben konvexe Bögon bildend, in das geschilderte Markfeld, den Rest der Markkappe, und zwar sehr deutlich nur in diesen eintreten, während der obere Raud vollkommen frei bleibt. Die drei geschilderten Fasern gehören den medialsten Faszikeln der Pars descendens des F. 1. i. an.

Die Figuren 11, 12, 13, Taf. IV, sind Abbildungen von Präparaten, die zwei anderen Gehirnen entnommen sind und die zur Illustration des Degenerationsmodus der Markbündel im äusseren Kniehöcker dienen sollen. In allen drei Fällen ist die Hemisphäre frontal geschnitten. Fig. 11, Taf. IV, bringt die Frontalebene aus einem Gehirn, in welchem ein Erweichungsherd im Schläfe-Scheitellappen ähnliche Degenerationsverhältnisse der Markbabnen geschaffen hatte, wie in unserem Falle. Im Zentrum des Präparates zwischen Thalamus und Fimbria des Ammonshornes erscheint der äussere Kniehöcker. Sein Spornteil fiel nicht mehr in die Schnittebene. Die innere, sclumächtigere Kniehöckerhälfte ist mit Markfasern besetzt, während die grössere, äusser $\theta$ faserleer ist, und nur im äusseren unteren Winkel eine dichtere kleine Fasergruppe auftaucht. Die Kniehöckerstrahlung sondert sich in einen sehr beträchtlichen dorsalen, entmarkten und in einen unbedeutenden ventralen, noch markscheidenführenden Faseranteil. Der erstere steht mit der faserleeren Partie des C. g. e. in Verbindung, während der letztere sich an die Fasergruppe des latero-ventralen Winkels anschmiegt. Nirgends gewahrt man im Kniehöckergebiet ein diffuses Auseinanderfahren der Markfäserchen, welchos bei teilweiser Degeneration eine gleichmässigeV Verminderung der Färbbarkeitzur Folge haben müsste. Stets einen segmentförmigen, scharf umschriebenen Faserausfall.

Die Figuren 12 und 13, Taf. IV, sind Wiedergaben von Präparaten aus einem Gehirn, dessen linksseitige Kalkarinarinde und nur diese fast vollständig darch einen Erweichungsherd zugrunde gegangen war. Das untere längsbündel ist, wio sich zeigt, isoliert zu sekundärer Degeneration gebracht worden. Fig. 12, Taf. IV, demonstriert das faserlose Areal des in seiner 
grössten Breite sich darbietenden äusseren Kniehöckers. Einige zarte, aus Markfäserchen geflochtenen Kränze und ein Markfaseranflug, wie der in der medialen Hälfte des markberaubten C. g. e., sind erbalten geblieben. In Uebereinstimmung mit der Faserbarheit des äusseren Knieböckers steht die totalo. Faserbarheit des F. l. i.

Aus den Präparaten beider Figuren gebt hervor, dass durch eine medialo Partie des äusseren Knieböckers Fasern ziehen, die mit dem unteren Längsbündel nichts zu tun haben.

Fig. 13, Taf. IV. Ein mehr kaudalwärts liegender Frontalschnitt. Dio topographische Situation wird durch den in seiner ganzen Höbe durchschnittenen Linsenkern bestimmt. In Gestalt gleicht der vordere äussere Kniehöcker einer lichten Krawatte, die allseits von einem dunklen, breiten Saum eingefasst wird. Auch hier stimmt Farblosigkeit des Areals des unteren Längsbündels mit der Farblosigkeit des Zentralgebietes des äusseren Kniehöckers. Nur vereinzelte Durchschnitte von Markbündeln in der medialen Hälfte verdunkeln dieselbe.

III.

Ueberblicken wir nochmals die Befunde an den einzelnen Präparaten und fassen wir das Gesantergebnis zusammen:

Die Durchschnitte der Figg. 7, 8, 9, 10, Taf. II u. III, beweisen durch. den Augenschein unwiderleglich, dass der basale Zug des F. l.i. mit seinem absteigenden Schenkel aus dem Spornteil des äusseren Kniehöckers entspringt, sie beweisen, dass der Austritt desselben' iu kompakter Bündelform erfolgt, und dass sich die Faserabgabe bestimmter Anteile des F. l. i. aus bestimmten Teilen des C. g. e., nicht aus dem ganzen äusseren Knieböcker vollzieht. Es ergibt sich ferner aus ihnen, dass der absteigende Schenkel des F.l.i. schräg medianwärts gestellt ist und mit der Sagittalen einen nach hiuten offenen Winkel bildet. Er gelangt daher nur bruchstückweise in den Sebnittebenen zur Anschauung. Mit unantastbarer Beweiskraft demonstriereu die Figg. 1,2,3, 4, Taf. I u. Il, die Existenz des vielumstrittenen Knies, welches sich nur bei geeigneter Schnittführung in seiner Kontinuität mit dem horizontalen Schenkel des F. 1. i. einerseits und mit der Pars descendens andererseits überblicken lässt. Eine Endigung oder ein Ursprung des basalen Bündels des F. l.i. im vorderen Schläfelappen ist hiernach wohl völlig ausgeschlossen.

Was nun das okzipitale Ende der basalen Bündel des F. I.i. anbetrifft, so gibt uns allerdings nur ein Präparat, und zwar das in der Fig. 2, Taf. I, reproduzierte, jedoch sehr bestimmten Aufschluss. Der horizontale dunkle Schenkel lässt sich bis zu den beiden hintersten und untersten Windungen, welche mit dem scharfen Vique d'Azyr'schen 
Markstreifen in der Hirnrinde ausgezeichnet sind, verfolgen. Es macht bei stärkerer Lupenvergrösserung den Eindruck, als ob die Markbahn nur in der vorderen der beiden Windungszipfel einliefe, doch lässt sich eine Faserabgabe auch in den hinteren nicht mit Sicherheit ausschliessen. Die beschriebene kleine Serie pathologischer Weigertpräparate befähigt uns also, das basale Bündel des F.l.i. von seinen Ursprungsganglien im Spornteil des äusseren Kniehöckers bis in die Rinde der Unterlippe der. Fissura calcarina zu verfolgen.

Welcher Kalkaringegend die beiden Windungszipfel angebören, wird uns bei Berücksichtigung der eingeschlagenen Schnittrichtung klar. Es wurde bereits wiederholt darauf hingewiesen, dass die Schnitte von hinten innen nach aussen vorne geführt wurden. Es mussten demnach jene Schnitte, welche bereits die temporale Querwindung mitnahmen, durch den vordereu medialen Hinterhauptslappen hindurcbgehen. Die Lokalisation der basalen Züge des unteren Längsbündels ist somit eine scharf umrissene.

Der hier erhobene Befund bringt kein neues Ergebnis hinsichtlich des Degenerationsmodus im äısseren Kniehöcker. Bereits im Jahre 1897 sprach S. Henschen auf dem XII. medizinischen Kongress zu Moskau "Ueber Lokalisation innerhalb des äusseren Knieganglions ${ }^{1}$ ". Er bebeschrieb im Vortrage einen von Wilbrand klinisch, von ihm ana. tomisch untersuchten Fall. Klinisch bot derselbe eine untere linke Quadrantenhemianopsie, welche von einer vollständigen linksseitigen Hemianopsie zurückgeblieben war. Dieselbe war ein Jahre hindurch anhaltendes. Dauersymptom. Nach dem Tode fand sich im okzipitalen Abschnitt des Thalamus eine hämorrhagische Zyste, welche bis zur oberen Grenze des Kniehöckers vordrang und sowohl den Traktus, wie die okzipitale Sehbahn intakt gelassen, aber die dorsale Hälfte des Knieböckers zerstört hatte. Im Anschluss daran war der dorsale Teil des F. l. i. sekundär entartet.

Henschen ${ }^{2}$ ) veröffentlichte noch einen zweiten Fall (Per Jönson) mit rechter unterer Quadrantenhemianopsie nach einer Zerstörung des dorsalen linken Kniehöckeranteils und darauffolgender sekundärer Degeneration des dorsalen F. l.i.

Dieser Fund bezeugt in Uebereinstimmung mit dem unseren, dass eine Dispersion der Fasern des F.l.i. im äusseren Knieböcker nach allen Richtungen hin nicht besteht, dass man, wie bei dem F. I. i. eine Trennung in einen dorsalen und ventralen ${ }^{3}$ ) Teil vornehmen kann, und

1) S. Henschen, Neurol. Zentralbl. 1898. Nr. 5. S. 1-7.

2) S. Henschen, Path. d. Geh. IV. S. 55. Taf. VII, VIII, IX.

3) Richtiger "dorsomedial" und "ventrolateral". 
Ursprung und Verlauf der basalen Züge des unteren Längsbündels. 319

dass sich beide nicht vermischen. Fr schreitet aber weiter in der Erkenntnis und erringt für diese beiden Teile physiologische Attribute, indem er dem dorsalen Kniehöckerfasersystem dle Fortleitıng der Reize der oberen Rindenbälften, dem ventralen diejenigen der unteren zuweist.

Selbst v. Monakow ${ }^{1}$, welcher, wie oben ausgefübrt, einer lokalisatorischen Netzhautwiederholung in der Sebstrahlung und im äusseren Kniehöcker abhold ist, musste 7 Jahre später das Zugeständnis machen, dass, wenn der obere Cuneus, $\mathrm{O}_{1}-\mathrm{O}_{3}$, und die dorsale Partie der zentralen Sehbahn zerstört seien, bloss die dorso-laterale Faserlage im F.l.i. und der fronto-mediale Teil des Corpus geniculatum externum der Degeneration verfalle.

Fine wichtige einschlägige Mitteilung verdanken wir Winkler ${ }^{2}$ ). Es werden von jhm 3 Fälle von Erweichungsherden, klinisch und anatomisch, genau untersucht vorgeführt. Er legte Frontalschnitte durch die hinteren Hemisphärenanteile und färbte dieselben nach Weigert-Pal.

Der erste Fall betrifft eine alte Erweichung der linken zweiten Schläfewindung und des Gyrus angularis. Der Herd durchbrach, wie Fig. 6 zeigt, im subkortikalen Marklager fast die ganze Hemisphärenbreite, um mit seinem medialen Ausläufer über dem Schweifkernschwanz zu enden. Der dorsale Teil des F.l.i. fand sich infolge der primären Läsion völlig sekundär degeneriert, ebenso die dorsale bzw. fronto-mediale grössere Hälfte des äusseren Kniehöckers. Fig. 5, welche ein naturgetreues Abbild einer Photographie ist, demonstriert die völlige Abwesenheit aller Fasern und Zellen in dem entarteten Kniehöckeranteil. Der Spornanteil, welchen Winkler Kauda nennt, besitzt normale Zellennester. Den horizontalen Schenkel des F. I. i. bildet er in der Fig. 7 scharf, in der Zeichnung, welche der Fig. 8 als Vorlage diente, nur andeutend ab, obgleich gerade eine genaue Topographie dieser Gegend wegen der hier vermutlich sichtbaren Einstrahlung jenes Restes des ventralen F. 1. i. von grosser Wichtigkeit gewesen wäre. Winkler ist sich über das Ende der ventralen Faserschicht ganz im Unklaren und vermutet ibr Ende in der Rinde des G. occipito-temporalis. Er sieht ein, dass die Rinde des Hinterhauptspoles nichts mit ihnen zu tun haben könne. Er meint, die Rinde der genannten Windung stehe desbalb mit dem F.l.i. in Konnex, weil seine Faserschicht im Temporallappen erhalten ge-

1) v. Monakow, Gehirnpathologie. 1905. S. 757.

2) C. Winkler, On localised atrophy in the lateral geniculate body causing quadrantic hemianopsia of both the right lower fields of vision. Folia nearobiologica. Sommer-Erg.-H. 1913. 
blieben war (siehe Fig. 7), während sie im Hinterhauptslappen vollkommen fehlte. Ein zweites, ihm zur anatomischen Untersuchung übergebenes Gehirn mit einer alten Zyste, welche den proximalen Abschnitt des Cuneus, den G. lingualis, den G. fusifurmis sowie den medialen Teil des G. occipito-temporalis in eine Membran verwandelt hatte, bot auf eiuer frontalen Schnittreihe, nach Weigert-Pal gefärbt, gerade das Negativ des ersten Falles, völligen Faserschwund des ventralen Abschnittes des F. I. i. und totalen Untergang der Zellen und Fasern im Spornteil des C. g. e. (siehe Figg. 12, 13). Dieser Fall ist Winkler ein entscheidendes Argument dafür, dass die ventrale Strahlung des F.l.i. aus dem proximalen Teil des Gyrus occipito-temporalis entspringe.

Diese Behauptung entbehrt jedoch einer zwingenden Begründung. Winkler berücksichtigt nämlich die nabeliegende Möglichkeit, dass die Cauda oder der Spornteil des C. g. e. in seinem zweiten Fall nicht deshalb sekundär entartet sein konnte, weil der proximale Teil des G. occipito-temporal is in einer Malazie aufgegangen, sondern weil durch dieselbe der vordere Abschnitt des $G$. lingualis und vor allem das ventrale Stratum selbst vernichtet worden war. Im-dritten Fall, in welchem es sich um eine Erweichung der basalen Windungen des linken Hinterhauptslappens gehandelt hat, blieben nichtsdestoweniger "the most ventral layers of the geniculo-cortical radiation and the most lateral parts of the cauda free from degenerative atrophy". Der G. ling. soll jedoch nur bis zu der Vereinigung der Fiss. calc. mit der Fiss. parietoocc. zerstört gefunden worden sein, er war somit in seinem vordersten Anteil gesund. Von diesem zogen die Fasern in den Spornteil des C. g. e., wi sich dies aus unseren Präparaten unabweislich ergibt, nicht aus dem unverietzten G. oceipito-temporalis.

Winkler's Fund einer vollkommenen Zell- und Faserentartung des äusseren Kniehöckers bat etwas für alle Stammganglien gesetzmässig Charakteristisches. Im Gegensatz zu den sekundären Degenerationen im Hemisphärenmark, welche konstant mit einer aufallenden Intaktheit der Ganglienzellen und tangentialen Markfasern nach der Rinde des grossen und des kloinen Gehirns einhergehen, sind die sekundären Entartungen im Thalamus, den Vierhügeln, der Brücke, der Medulla oblongata stets total. Auf Weigertpräparaten finden sich an der Stelle des vollkommen zugrunde gegangenen Gewebes weisse Flecke. Wir erkennen hieraus einen fundamentalen morphologischen Unterschied im feineren Aufbau der mit einer Rinde bekleideten und der eine solche entbehrenden Hirnorgane. Während die Ersteren keine Ganglienzellen 
besitzen, deren markscheidenführende Ausläufer eine gegenseitige Vereinigung herstellen, sondern nur längere Fortsätze, die mit den Sinnesflächen oder der Hirnrinde zusammenhängen können, sind die Kortexorgane, das Grosshirn und das Kleinhirn, in ihrer grauen Decke mit reichlichen markhaltigen Binnenfasern, die Aufang und Ende in derselben haben, mit Assoziationsfasern ausgestattet. Die Stammganglien, das Zerebellum ausgenommen, sind durch Barheit dieser ausgezeichnet.

Dieser anatomischen Erkenntnis fügt sich die klinische Tatsache, dass Unterbrechungen der zentralen Sehbahn dieselben Symptome geben wie Zerstörungen ihrer $Z$ wischenstation im Sehhügel; aus dieser klinischen Identität der Pathologie beider Hirnabschnitte ist ein Schluss auf eine physiologische Identität derselben, welche hinwieder auf eine Identität in geweblichen Aulbau zurückverweist, wohl gerechtfertigt.

Es ist zwar richtig, dass den Ganglienkränzen im äusseren Kniehöcker dichte Gewinde aus Markfäserchen entsprechen, gleichwie einer besonderen Zytoarchitektonik der Hirnrinde eine bestimmte Myeloarchitektonik parallel geht. Der wesentliche Unterschied zwischen diesen beiden Markstrukturen ist jedoch der, dass der Faserfilz des Kniehöckers mit der entarteten Faserung des F. l. i. gleichzeitig verscbwindet, während das Tangentialfasernetz der Hirnrinde auch bei Jahre alten Faserdegenerationen fast ganz normal bleibt. Dasselbe ist auch bei Entartungszuständen im Kleinhirn der Fall. Die dichten, feinfaserigen Markgewinde des Kniehöckers können daher sehr wohl feinste Aufsplitterungen der Sehbahn und des Tractus opticus bedeuten, woraus jedoch keineswegs, wie v. Monakow annimmt, eine Diffusion der physiologischen Empfindungsreize und Umordnung der peripheren Reizanordnung gefolgert werden müsste. Jede eintretende Faser splittert sich an einer bestimmten Gruppe von Ganglienzellen auf, ebenso wie die austretende Faser aus einer bestimmten Ganglienzelle entspringt. Sie behält dadurch, obwohl sie mit mehreren Ganglienzellen in Verbindung tritt, ihre lokalisatorische Signatur. Indem so durch eine einzelne Faser eine Gruppe von Ganglien erregt werden kann, wird jede Ganglienzelle von mehreren Fasern erregt, woraus eine enorme Reizverstärkung für gewisse Ganglien resultieren würde, denen dann die Fortleitung der in der Netzhaut und dem Traktus bereits erfolgten Anordnung der Reize nach der Hirnrinde hin zufiele. Den Ganglien des Kniehöckers kommt demnach keine assoziierende, sondern eine die Intensität des Reizes steigernde Leistung zu. Die Ausdehnung der Aufsplitterungen erstreckt sich, soweit ich dies wahrnehmen komte, niemals auf Ganglienzellen, 
die sowobl im Spornteil als auch im Hilusteil, d. h. Knieböckerkörper liegen, sondern auf Ganglienzellen, die über- und nebeneinander liegen.

Es ist von nicht geringem Interesse, wenn wir bei Minkowski ${ }^{1}$, welcher bei Hunden Exstirpationsversuche vorgenommen hat, Vorstellungen über die zentrale Projektion der Netzhaut im Kniehöcker und in der Hirnrinde antreffen, welche den hier vorgetragenen nahe verwandt sind. Minkowski folgert aus seinen Experimenten, dass je stärker die physiologische Inanspruchnabme eines Netzhautelementes sei, welche durch das Mass seiner Entfernung von der Stelle des direkten Sehens bestimmt werde, desto stärker und umfangreicher bildeten sich die Kollateralen in den Endbäumchen der zugehörigen Optikusfasern im Corp. gen. ext. und deu kortikopetalen Sehstrablungsfasern in der Hirnrinde aus. Auf S. $302^{2}$ ) ist dies skizzenhaft dadurch versinnlicht, dass ein mit ungleich grossen, sich teilweise deckenden Kreisen besetztes Oval gezeichnet ist, in welchem die grössten Kreise der Aufsplitterung der stärker in Anspruch genommenen Fasern entsprechen, da dieselben mit einer grösseren Anzahl von Ganglienzellen in einem funktionellen Konnex stehen, während diejenigen, deren Endausbreitung in einem engeren Ganglienkreis stattfindet, nur mit wenigen Kollateralen ausgestattet ist. Nach Minkowski wächst also die funktionelle Intensität mit der Zahl der eingeschalteten Nervenkörper, wobei die wunderbar zweckmässige Natureinrichtung besteht, dass eine Reizverstärkung bereits in den 'subkortikalen Hirnzentren vor sich geht. Die retinale Lokalisation im Gehirn folgt daher, womit wir durchaus übereinstimmen, nicht in einer Projektion einzelner Fasern und Zellen, sondern gestaltet sich in einem Neben- und teilweise Uebereinander funktionell selbständiger Projektionskreise. Dabei ist eine örtliche Trenuung derselben nach dorsalen und ventralen, nach frontalen und okzipitalen Bezirken sicher vorhanden und daher isolierte funktionelle Ausfälle der Peripherie bei zirkumskripten Zerstörungen des Zentrums wohl erklärbar.

\section{Erklärung der Abbildungen auf Tafeln I-IV.}

Die für die Weigert-Palfärbung in üblicher Weise vorbebandelte rechto Gehirnhälfte wurde so aufgebettet, dass der Hinterhauptslappen höher gelagert wurde als der Schläfelappen. Es sollte damit bezweckt werden, dass dia Lippen der Fissura calcarina und die temporale Querwindung in einer Sohnittebene zur Anschanung gelangen. Die erträumte physiologische Bedeutung des F.l.i. war ja die funktionelle Verbindung der Seh- mit der Hörsphäre. Es

1) Minkowski, Zur Physiologie der Sehsphäre. Arch. f. d. ges. Physiologie. Bd. 141.

2) Derselbe, l. c. 
war daber wichtig zu untersuchen, ob solche direkte anatomische Konnexe im F.l.i. wirklich vorhanden wären. Die Besichtigung der gelungenen Photographien, welche selbst einzelne Fasern naturgetreu reproduzieren, gibt, ich glaube, eine hinlänglich klare Antwort:

Fig 1, Taf. I. Die vordere Hemisphärenhälfte. Eine Erweichungszyste im Parietallappen hat eine fast vollständige Entartung des Temporallappens zur Folge gehabt. Die Spitze der ersten Schläfewindung, sowie die vordere Hälfte der temporalen Querwindung sind von kleinen malazischen Lücken durchsetzt, von denen zwei mit H signiert sind. Auf hellem Grunde erscheint F.1.i., der Fasciculus longitudinalis inferior, ein spitzes Knie bildend und linienscbarf nach oben zu abbrechend, weil aus der Scbnittebene tretend. Steigt man eine vertikale Linie verfolgend, vom Knie aufwärts, so stösst man auf die temporale Querwindung Tp; welche aller langläufigen Einstrahlungen beraubt ist. Dass der F.l.i. keine Zuzüge aus den 3 temporalen Windungen $\mathrm{T}_{1}, \mathrm{~T}_{2}, \mathrm{~T}_{3}$ oder $\mathrm{Tp}$ erhält oder in dieselben entsendet, ist offenbar. Das Stratum sagittale internum Stri., sowio die Tapetumschicht Ta sind äusserst reduziert. Ueber der Fissura Sylvii FS steigt das Operculum Rolandicum mit seinem Uebergang in das Stirnhirn empor. Ca vordere, Cp hintere Zentralwindung, c Zentralfurche, $\mathbf{F}_{\mathbf{3}}$ dritte Stirnwindung, pr Präzentralfurche, rc Retrozentralfurche, Pa Schoitellappen. Eine sekundäre Entartung in das Operc. Rol. lässt sich nur bis zum Rindengrunde der ersten Sekundärfurche (vom temporalen Ende der FS an gerechnet) und der Rinde ganz naheliegend verfolgen.

Fig. 2, Taf. I. Die vorgeführte Schnittebene liegt etwas mehr der Mittellinie $\left.\mathbf{z a}^{1}\right)$. Der primäre parietale Herd $(\mathrm{H})$ tritt im Präparat als ein runder Substanzverlust hervor, um welchen das Eigenmark des Scbeitellappens $P$ sekundär entartet ist. Die Malazie unterbricht die dorsalen Bündel des F.l.i., welche vom Herd stirnwärts entartet sind, wahrend ihr okzipitales Stück, welches in den hinteren unteren Okzipitalkappen hinabsteigt und dort sein Ende findet, zum grössten Teil normale Markscheiden besitzt. Einzelne Fasern, welche über oder unter dem Herd $(\mathrm{H})$ von hinten nach vorne ziehen and hinabsteigen (F), teilen die entmarkte Babn in scheinbare Schichten. Oberflächliche makroskopische Besichtıgung mag eine Einstrahlung in die temporale Querwindung vortäuschen. Bereits schwache Lupenvergrösserung zerstreut dieses Trugbild. Auf entmarktem Grunde überblicken wir ein grosses Verlaufsstück des basalen F.l.i. mit seiner Endigung irn G. lingualis (Ling.), des Hinterbauptlappens (0). Die Einstrablung in diese Windung ist makro- und mikroskopisch wahrnehmbar. Der F.l.i. biegt im spitzen Winkel nach oben, und bricht plötzIich ab, gleichwie auf der Fig. 1, Taf. I. Das Stratum sagittale internum Sti und das Tapetum $\mathrm{Ta}$ sind stark geschrumpft. Eine sehwarze, den Ventrikel

1) Ich gebe die Distanz zwischen den hier dargestellten Ebenen nicht an, weil derartige numerische, nicht kontrollierbare Bestimmungen für den zu beweisenden Gegenstand irrelevant sind. Auch beschränkte ich mich auf die Schilderung der beigegebenen Photographien, da man sich über nicht selbst geseheno Präparate kein Urteil bilden kann. 
einfassende, isolierte Leiste gehört dem Tapetum an. $\mathrm{T}_{1}, \mathrm{~T}_{2}, \mathrm{~T}_{3}$ die erste, zweite und dritte Schläfewindung. Die Spitze, sowio die obere Hälfte der Ersten, sind von einem primären Herd (H) zerstört. Das gesamte Mark der zweiten Schläfewindung $\mathrm{T}_{2}$ ist sekundär entartet. Weder Abgänge aus dem F.l.i. noch Zugänge zu demselben aus den Schläfewindungen sind sichtbar. Die Lichtungen im zentralen Mark der basalen Schläfewindungen erklären sich aus dem Faserverlust der eintretenden Tapetumfasern. FS Fissura Sylvii, $\mathbf{F}_{\mathbf{3}}$ dritte Stirnwindung, $\mathrm{Ca}, \mathrm{Cp}$ vordere, hintere Zentralwindung, pr Sulcus praecentralis, c Zentralfurche, rc Sulcus retrocentralis, Cb Sagittalabschnitt der rechten Kleinhirnhemisphäre.

Fig. 3, Taf. I. Ein vorderes Hemisphärensegment. $\mathrm{T}_{1}, \mathrm{~T}_{\mathbf{2}}, \mathrm{T}_{\mathbf{3}}$ wie oben. Nicht nur die erste, auch die zweite Schläfowindung ist von Malazien durchlöchert und zerrissen (siehe die Buchstaben $\mathrm{H}$ in $\mathrm{T}_{2}$ ). Daraus erklärt sich der völlige Markverlust der $\mathrm{T}_{2}$. Der spitze Winkel, in welchem der F.l.i. sich nacb oben wendet, hat sich erweitert, die Pars descendens ist breiter, weil schräg getroffen, und länger geworden, das Stratum sagittale internum und das Tapetum siad stark reduziert und markarm. Wieder keine Abgänge von Fasern aus, noch zu dem F.l.i. in das Mark der umliegenden Windungen, auch nicht in die temporale Querwindung Tp. Ca, Cp, F $3, c$, pr, FS, Cb auch der Rest des F.l.i. wie oben. $\mathrm{F}_{3}$ Op Pars opercularis frontalis, $\nabla$ Sulcus verticalis. $F_{3}$ tr Pars triangularis der dritten Stirnwindung. Die vom Scbläfelappen durch das Operculum Rolandicum in die dritte Stirnwindung ziehende Aufhellang des zentraleren Marks weist anf eine Markentartung der langen Elemente des Bogenbündels der Sylvischen Spalte hin.

Fig. 4, Taf. II. Die winkelige Umkehr des F.l.i. hat, sich zu einer bogenförmigen rundend, die Gestalt oines Knies vollendet. Das Stratum sagittale internum (Sti) und das Tapetum (Ta) sind ganz faserleer, so dass eine Trennung zwischen diesen beiden Schichten ganz ausgesohlossen ist. Die zweite Schläfewindung $\left(\mathrm{T}_{2}\right)$ ist durch eine Erweichung mebrfach durchlöchert. Ein Herdchen H tritt bis an die Konvexität des Knies heran, Der ganze Schläfelappen $\left(\mathrm{T}_{1}\right.$, $\mathrm{T}_{2}, \mathrm{~T}_{9}$ ) ist vollständig entmarkt. Eine sekundäre Degeneration im F.l.i. ist nirgends zu entdecken, obschon entartete Fasern durch seine Bündelgruppen in das zu einem gerneinsamen Strombett zusammengeflossene Stratum sagittale internum und Tapetum bineinziehen. D degeneriertes Faserkonvolut des dorsalen F.l.i. mit einzelnen, der Entartung entgangenen, weil über und neben dem primären Herd verlaufenden Fasern. Ueber diesen der normale Stabkranz (St) aus intakten Windungsgebieten. I Inselwindungen, $\mathrm{F}_{2}$ zweite Stirnwindung, $\mathrm{F}_{3}$ dritte Stirnwindung. $\mathrm{Ca}, \mathrm{Cp}, \mathrm{Cb}, \mathrm{pr}, \mathrm{c}$ wie oben. $\mathrm{F}_{2}$ zweite Stirnwindung.

Fig. 5, Taf. II. Einen Sektor aus der Grosshirnhälfte darstellend. Ein Defekt in der zweiten Schläfewindung scheint den F.l.i., in dem er die Runde des Knies bildet, zu durchbrechen. Derselbe kann aber nicht ein primärer Herd sein, da die Markscheiden an den Bündeln vor und hinter demselben vorhanden sind. Der absteigende Schenkel des F.l.i. ist in seinem grössten Verlaufsstüok hior getroffen. Er wendet sich an der Linsenkernbasis hinziebend, mit Andeutung einer Spiralentour nach abwärts. An sein oberes Ende schliesst 
sich eine faserleere breite Zone D, die sich aus degeneriertem dorsalen F.l.i. und absteigenden Fasern des zerstörten Parietallappens zusammensetzt. An diese grenzt die dunkle, aus den gesunden Stabkranzstäben konstituierte Bündelmasse der inneren Kapsel Ci. Auf dem Zerebellum $\mathrm{Cb}$ rubt die dritte Scbläfewindung $\mathrm{T}_{3}$, über welchem sich die vorderen Ausläufer des G. hippocampi, die Impressiones digitata Im erbeben. Aus diesen entwickelt sich nach vorne zu, bereits bemerkbar, das Ammonshor (A).

Fig. 6, Taf. II. Skizze eines äusseren Kniehöokers, zum leiehteren Verständnis der folgenden Figuren, hier eingefügt. II Hilusteil, S Spornteil, T. Traktusteil. Die Lage der punktierten Linien zeigen die Neigung des Messers zur Vertikalen an, mit welcher die Hemisphärenebenen geschnitten wurden. Der ventrolaterale Teil der Sehstrahlung, durch kräftige Schraffierung ausgeführt, ist intakt, der dorsomediale feinpunktiert, sekundärentartet und markscheidenlos. Denkt man sich durch die einzelnen Linien Sagittalschnitte gelegt, so erhalten wir durch die Linie 7 den Austritt des F.l.i. aus dem lateralsten Spornteil, wie er auf der nächsten Fig., der Fig. $7 \mathrm{zu}$ Tage tritt, durch die folgenden Linien 8, 9, 10. Die Formationen, unter welchen der noch markscheidenfübrende und der erkrankte F.l.i. aus den einzelnen Regionen des äusseren Kniehöckers hervorgeht.

Fig. 7, Taf. Il. Ca, Cp, $\mathrm{F}_{2}, \mathbf{F}_{3}, \mathrm{~J}, \mathrm{FS}, \mathrm{Cb}$, o, pr, $\mathrm{f}_{2}$ wio oben. Coa vordere Kommissur. F. l. i. unteres Längsbündel, an zwei Stellen seines Verlaufsstückes durch Zeiger signiert. Das Einemal bei seinem Abstieg zur Scbläfelappenbasis, das Anderemal bei seinem Austritt aus dem kleinen Längsschnitt des Spornteils des C.g.e. Natürlich nimmt nicht etwa das dicke, breite Markfaserkonvolut, welches dem minimalen linsenförmigen Sagittalschnitt des Spornteils aufgesetzt ist, aus diesem allein seinen Ursprung. Der Schrägschnitt bedingt vielmehr das Mitbetroffensein von Fasern, welche aus einer mehr medialwärts gelegeneren Ebene des C.g. . hervorgehen. (Siebe Fig. 7, Taf. II, den Lauf der punktierten Linie durch die normalen Markfaserbündel.) Coa vordere Kommissur, T Spitze des Schläfelappen, welcher die erste und zwoite Schläfewindung vereinigt. FH Fasciculus gyri hippocampi, D weist auf ein breites Feld degenerierter Fasern hin, wolches sich nach binten und innen an die innere Kapsel anschliesst. Pu das geschrumpfte, eingesunkene P'ulvinar.

Fig. 8, Taf. III. Ca, $\mathrm{F}_{2}, \mathrm{~F}_{3}, \mathrm{~J}, \mathrm{~T}, \mathrm{Coa}, \mathrm{FH}, \mathrm{Cb}, \mathrm{D}, \mathrm{Pu}, \mathrm{c}, \mathrm{pr}, \mathrm{f}_{2}$, fs wie oben. F.1.i. deutet vorne lateral auf absteigende Fasern, hinten medial auf die eben aus dem Spornteil austretende Markmasse hin, wie dies in der vorhergehonden Figur geschehen ist. C.g.e. das sich vergrössernde Sagittalbild des Spornteils.

Fig. 9, Taf. 11I. Ca, Cp, $\mathrm{F}_{2}, \mathrm{~F}_{3}, \mathrm{~J}, \mathrm{~T}, \mathrm{Coa}, \mathrm{Cb}, \mathrm{FH}, \mathrm{D}, \mathrm{Pu}, \mathrm{c}, \mathrm{pr}, \mathrm{f}_{2}$, fs wio oben. Der Kniehöcker hat hier die Gestalt eines Ovals angenommen, welches sich der Länge nach in zwei ungleich grosse Hälften teilt. Die grössere, obere ist tiefdunkel, aus dichtstehenden, hämatoxylingeschwärzten Markfasern des F.l.i. zusammengesetzt, welcher aus den Ganglienkränzen im Abbang des Spornteiles, dessen innerer Markfasergehalt durcb die schwärzlichgraue Färbung zum Ausdruck gelangt, eben hervorgeht. Der absteigende Schenkel des F.l.i. 
ist hier nur durch einzelne, wellenförmig geschwungene Fäserchen vertreten, welche noch aus dem schmalen Sporn ibren Ursprung herleiten. Zwischen dem C.g.e. und dem hellgrauen Degenerationsfeld D, ein kräftiges Faserbüschel aus der Faserung des Globus pallidus, sich im Emporsteigen sammelnd, und das faserleere Areal $\mathrm{D}$ von dem geschrumpften Sehbügelpolster $\mathrm{Pu}$ trennend, um sich den Paketen der inneren Kapsel zu innerst anzureihen: die Linsenkernschlinge LKS.

Fig. 10, Taf. III. Ca, Cp, F $, \mathrm{F}_{3}, \mathrm{~J}, \mathrm{~T}, \mathrm{Coa}, \mathrm{Pu}, \mathrm{D}, \mathrm{FH}, \mathrm{LKS}, \mathrm{c}, \mathrm{pr}, \mathrm{f}_{\mathbf{2}}$, fs wie oben. Das C.g.e. hat jetzt die Form einer Bischofsmütze, deren Basis nach vorn unten und deren Spitze nach hinten oben gekehrt ist. Von dem vorderen Winkel des Kniehöckerganglions lassen sich drei Fasern verfolgen, die in mehrfachen Bögen, sich nach abwärts wendend, mit den Ueberbleibseln der Pars descendens des F.l.i. eine Kontinuität bilden. Die dunkle, unscharf begrenzte Stelle im Zentrum erklärt sich aus einer Aussaat von Faserstümpfen, die infolge des schräg sagittalen Durchschnittes noch in die vorliegende Ebene fallen und in dem Ganglion zu liegen scheinen.

Fig. 11, Taf. IV. C.g. e. das Corpus genioulatum externum in einem Falle von Erweichung des linken Parietotemporallappens (siehe über die Einzelheiten derselben meine Arbeit: „Die Diagnose auf Erkrankung des linken G.angularis". Monatsschr. f. Psych. u. Neurol. Bd. 22. H. 2). Der ventrale Teil des F.l.i. Fliv. hat seine Markscheiden bewahrt, der dorsale Flid verloren. Wir sehen die markscheidenlosen Fasern des Letzteren in geschlossenem Zuge in das C.g.e. eintreten. Da der äussere Kniehöcker nicht ganz vertikal getrofien ist und die latero-ventrale Hälfte des F.l.i. kaudaler als die mediko-dorsale ihren Ursprung nimmt, so sehen wir die Gegend der Ausgangspunkte jenes nur zum kleinsten Teile im vorliegenden Schnittbild. Die medialsten, vordersten Abschnitte des C.g.e. erhalten ihr Mark offenbar nicht vom F.l.i., wie die Betrachtung der folgenden Fig. 12, Iaf. IV lehrt. C.g.i. innerer Kniehöcker, CA Ammonshorn.

Fig. 12, Taf. IV. Querabschnitt eines linken äusseren Kniehöckers bei vollständiger sekundärer Entartung des F.l.i. infolge einer auf die Lippen der Fissura calcarina beschränkten alten Malazie. Das ganze C.g.e. ist der kräftigen Einstrahlungen des F.l.i. beraubt. Die das Ganglion allseits einrahmende Markborte, die in seinem Innern mehr minder ausgeprägten Markleisten, der aus feineren Fasern über den dorsomedialen Teil geworfene Scbleier entbohrt dahor eines Zusammenhangs mit den Bündeln des F.l.i. Das Stratum sagittale internum verändert, indem es sich hinauf zum Thalamus begibt, seine Lage, in dem es nach aussen und oberhalb vom F.l.i. verläuft. CA wie oben.

Fjg. 13, Taf. IV. Der hinterste Teil desselben äusseren Kniehöckers. Dieser ist bis auf die breite, ihn rings einfassende, Markborte, welche sehr wahrscheinlich aus 'Traktusfasern gebildet wird und ganz schwachen, queren, nur angedeuteten Markleistchen, in seiner medialen Hälfte vollständig entmarkt. Diese Entmarkung D korrespondiert mit dem gleichen Zustand des F.l.i. Das Stratum sagittale internum Sti, links unten noch im Quersebnitt getroffen, das in seiner stattlichen Breite und charakteristischen Anordnung 
Ursprung und Verlauf der basalen Züge des unteren Längsbündels. 327

seiner Elemente keine pathologische Einbusse verrät, entlässt nach oben innen bin sich entbündelnde längsgetroffene Fasern, welche teilweise in den Sehbügel einstrahlen, teilweise sich dem Hirnschenkelfuss zugesellen, obgleich sie die Wölbung des in den Kniehöcker sich einsenkenden F.l.i. nachahmen und am normalen Markfaserpräparat eine Einstrahlung in denselben vortäuschen, wie dies von vielen Autoren behauptet wird. Wie die den Figg. 12 und 13, Taf. IV zu Grunde liegenden Präparate jedoch bewoisen, oxistiert oin Zusammenhang zwischen Radiatio thalamica und C.g.e. nicht. CA wie oben. 